\title{
Ocupação inicial das Américas sob uma perspectiva bioarqueológica
} The initial settlement of the Americas from a bio-archaeological perspective

\author{
Pedro Da-Gloria (10 \\ Universidade Federal do Pará. Programa de Pós-Graduação em Antropologia. Belém, Pará, Brasil
}

\begin{abstract}
Resumo: A ocupação das Américas tem sido discutida cientificamente desde o século XIX, gerando uma infinidade de modelos explicativos. Por outro lado, há limitações das evidências empíricas das primeiras ocupações, causadas por problemas de preservação e pela baixa visibilidade arqueológica. Nesse aspecto, o uso de dados biológicos de populações humanas atuais e antigas tem fornecido informações cruciais para a interpretação dessas primeiras ocupações. Sob uma perspectiva bioarqueológica, ou seja, através do estudo dos remanescentes biológicos humanos em contexto arqueológico, este texto sintetiza o atual entendimento sobre a rota de entrada, a data de entrada inicial, o número de migrações, a subsistência e os rituais mortuários dos primeiros americanos. Os resultados desse panorama sintético indicam que há temáticas de alto consenso (rota de entrada), de consenso intermediário (data de entrada) e de baixo consenso (número de migrações). Por outro lado, temáticas como a saúde e o modo de vida dos habitantes antigos das Américas ainda carecem de estudos mais aprofundados. Este texto ressalta a importância do conhecimento bioarqueológico para a formulação de modelos de ocupação, buscando incorporar de forma equilibrada evidências da América do Sul e do Norte.
\end{abstract}

Palavras-chave: Esqueletos humanos. DNA antigo. Primeiros americanos. Craniometria. Dentição humana. Arqueologia americana.

Abstract: The occupation of the Americas has been discussed scientifically since the nineteenth century, generating countless explanatory models. On the other hand, empirical evidence of the first occupations is limited because of preservation problems and low archaeological visibility. In this regard, the use of biological data from living and ancient human populations has provided crucial information for interpreting these early occupations. From a bioarchaeological perspective (in other words, from the study of human biological remains within an archaeological context), this present study brings together current understanding on the route of entry, the date of initial entry, the number of migrations, subsistence, and mortuary rituals of the first Americans. The results of this overview indicate that there are topics with high consensus (route of entry), intermediate consensus (date of entry), and low consensus (number of migrations). Meanwhile, the health and lifestyle of the ancient inhabitants of the Americas still require further study. This text highlights the importance of bioarchaeological knowledge in formulating occupation models while incorporating evidence from both South and North America in a balanced manner.

Keywords: Human skeletons. Ancient DNA. Early Americans. Craniometry. Human dentition. American archeology.

DA-GLORIA, Pedro. Ocupação inicial das Américas sob uma perspectiva bioarqueológica. Boletim do Museu Paraense Emílio Goeldi. Ciências Humanas, Belém, v. 14, n. 2, p. 429-457, maio-ago. 2019. DOI: http://dx.doi.org/10.1590/1981.81222019000200009.

Autor para correspondência: Pedro Da-Gloria. Universidade Federal do Pará. Programa de Pós-Graduação em Antropologia. Instituto de Filosofia e Ciências Humanas. Laboratório de Antropologia Arthur Napoleão Figueiredo. Cidade Universitária Prof. José Rodrigues da Silveira Netto. Belém, PA, Brasil. CEP 66075-110 (pedrodagloriaufpa@gmail.com).

Recebido em 17/08/2018

Aprovado em 30/11/2018
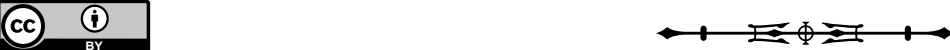


\section{INTRODUÇÃO}

A ocupação inicial das Américas tem gerado inúmeras controvérsias e debates desde o século XIX, quando as primeiras teorias científicas começaram a ser propostas em relação a esse assunto (Hrdlička, 1912). O investimento em escavação e pesquisa foi e continua sendo desigual no seu extenso território. Muitos modelos de ocupação que eram condizentes com o registro arqueológico norteamericano ignoraram as evidências da América do Sul, ou mesmo demoraram para incorporá-las (Dillehay, 2000). Ao mesmo tempo, quanto mais antigas são as ocupações, menor a visibilidade arqueológica, especialmente em áreas tropicais, que, em geral, impedem a adequada preservação de material orgânico, devido a fatores como temperatura, umidade, pH e ação bacteriana (Collins et al., 2002; Hedges, 2002). A soma desses fatores tem gerado uma infinidade de modelos de ocupação das Américas, sendo que muitos deles apresentam diferentes evidências empíricas (Dillehay, 2009). Dentro desse contexto de multiplicidade de modelos, a incorporação de novos métodos de análise é uma maneira importante de refinar empiricamente os modelos científicos existentes e de trazer à luz dimensões antes não observadas. Nesse aspecto particular, as evidências biológicas (ossos, dentes e DNA humanos) obtidas a partir de populações atuais e de sítios arqueológicos têm trazido novas e cruciais informações para o entendimento da chegada dos humanos às Américas, e no que tange particularmente à área de genética têm desencadeado um ritmo frenético de produção de novos dados. Por outo lado, essa aceleração da produção de resultados empíricos necessita de um exercício de síntese e de reflexão, que incorpore também as evidências arqueológicas e as obtidas de estudos clássicos, tais como os de morfologia esqueletal humana, tanto a partir de estudos oriundos da América do Norte e do Sul. Este texto busca abordar as principais questões relacionadas à ocupação inicial das Américas sob uma perspectiva bioarqueológica, a fim de produzir uma reflexão que incorpore as novas evidências empíricas de forma integrada com os modelos arqueológicos.
A bioarqueologia é definida aqui como o estudo dos remanescentes biológicos humanos em contexto arqueológico, e tem produzido uma quantidade significativa de dados sobre história populacional e modos de vida no passado (Larsen, 2015). Na temática da ocupação inicial das Américas, quatro questões têm recebido contribuições significativas de dados biológicos, a dizer, rota de entrada, data de entrada inicial, número de migrações e modos de vida (subsistência e rituais mortuários). $\bigcirc$ objetivo deste texto é revisar e refletir criticamente sobre essas quatro questões, abordando métodos de análise e evidências científicas recentes. Este texto busca trazer uma visão equilibrada entre modelos oriundos de pesquisadores da América do Norte e do Sul, reportando estudos brasileiros, sempre que forem relevantes ao tema.

\section{ROTA DE ENTRADA PARA AS AMÉRICAS}

A rota de entrada é a primeira questão básica a ser respondida para o entendimento das primeiras ocupações das Américas. A semelhança física e genética dos ameríndios com populações asiáticas tem sugerido a Ásia como local de origem da população nativa americana. Desde os primeiros relatos de viajantes, notou-se semelhanças morfológicas do cabelo, do formato da face e das dobras do olho entre asiáticos e ameríndios (Crawford, 1998). Essas semelhanças também foram observadas na morfologia craniana e dental por antropólogos físicos do começo do século $X X$. Baseado em análises de esqueletos humanos, Hrdlička (1921, 1932, 1937), por exemplo, propôs o conceito de homótipo americano, observando uma homogeneidade morfológica entre ameríndios, e sugerindo uma origem asiática recente para essas populações. Estudos recentes de morfologia dental confirmaram esses estudos clássicos quanto à semelhança entre ameríndios e asiáticos. $\bigcirc$ padrão Sinodonte de traços não métricos dos dentes é encontrado em populações da China, da Mongólia, da Sibéria e em nativos americanos. Esse padrão inclui, entre outros traços, altas frequências de incisivo em forma de pá, primeiro pré-molar superior com raiz única e primeiro

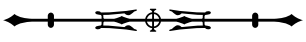


molar inferior com três raízes (Turner II, 1987, 1990; Scott et al., 2018).

Nas últimas décadas, a semelhança entre populações asiáticas e ameríndias foi também constatada em estudos com dados moleculares. Usando grupos sanguíneos e haptoglobinas concluiu-se que as populações da Ásia ou da Polinésia deram origem aos nativos da América do Sul (Salzano; Callegari-Jacques, 1988). Mais especificamente para o caso de populações amazônicas, polimorfismos do sistema leucocitário genético humano (HLA) e da imunoglobulina IgG forneceram evidências de uma origem siberiana para essas populações (Black et al., 1991). Em conjunto, os estudos com polimorfismos proteicos, imunoglobulinas e genes do sistema HLA apontaram para a Ásia como local de origem de populações nativas das Américas (Schurr, 2005). Dados genéticos têm fornecido contribuições adicionais para essas questões. Os quatro haplogrupos principais de DNA mitocondrial em ameríndios, classificados como A, B, C e D, também estão presentes em populações asiáticas (Schurr et al., 1990; Llamas et al., 2016). Da mesma forma, o cromossomo $Y$, transmitido somente pela linhagem paterna, é encontrado nas Américas em dois haplogrupos principais: $\mathrm{Ce} Q$, ambos derivados de populações asiáticas (Zegura et al., 2004). Dados de DNA autossômico, com uma quantidade ainda maior de informação genética, também têm corroborado a origem asiática de populações ameríndias (Wang et al., 2007; Reich et al., 2012). Em síntese, a semelhança biológica entre ameríndios e asiáticos tem sido uma forte sustentação para as rotas de entrada para as Américas de populações vindas da Ásia.

O estreito de Bering, localizado no nordeste asiático, tem sido considerado, desde os primeiros estudos científicos do século XIX, como a principal rota entre Ásia e América do Norte. Durante o final do Pleistoceno, ou seja, entre 30 e 11 mil anos atrás', o estreito de Bering era uma rota contínua de terra, resultado do nível do mar mais baixo do que o atual em até cem metros (Elias, 2002; Hu et al., 2010; Wooller et al., 2018). Nesse período, essa conexão criou uma área de terra contínua entre Ásia e América do Norte, chamada de Beríngia. Essa rota é hoje a mais aceita para a entrada de populações asiáticas nas Américas.

Embora a grande maioria dos estudiosos dos primeiros americanos acredite na rota de entrada pela Beríngia, há grupos minoritários que defendem a migração por outras rotas. Um exemplo histórico é a ideia de que os primeiros americanos chegaram na América do Sul pela Polinésia. Essa ideia foi defendida por Paul Rivet, baseando-se na semelhança craniana dos antigos habitantes do Equador, de Lagoa Santa e da Polinésia (Rivet, 1957). Aspectos tecnológicos parecem não ter sido um empecilho para uma travessia oceânica, uma vez que, em 1947, Thor Heyerdahl construiu uma jangada e conseguiu navegar do Peru até as ilhas da Polinésia, sem recursos tecnológicos sofisticados. Essa viagem foi conhecida como expedição Kon-Tiki (Heyerdahl, 2013). Porém, evidências arqueológicas de ocupação da Polinésia datam de, no máximo, 3 mil anos atrás (Kirch, 2017), mostrando que essa não é uma rota viável para as ocupações mais antigas da América do Sul. Por outro lado, há evidências genéticas de contato relativamente recente entre populações da Polinésia e da América do Sul (Moreno-Mayar et al., 2014).

Uma rota direta da África para a América do Sul pelo oceano Atlântico também tem sido aventada por alguns pesquisadores brasileiros (Guidon, 2014), porém não há evidências biológicas nem arqueológicas para ela. A observação de que a morfologia craniana dos antigos habitantes da América do Sul é similar à de populações africanas (e australo-melanésiacas) recentes, especialmente os crânios antigos oriundos de Lagoa Santa, Minas Gerais (Neves; Hubbe, 2005), é melhor explicada pela presença de uma morfologia ancestral oriunda da África ocupando

\footnotetext{
1 Todas as datas radiocarbônicas deste texto são reportadas em anos calibrados, pois, dessa forma, elas podem ser comparadas com estimativas genéticas de idades de coalescência.
}

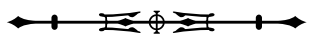


todo o Velho Mundo durante o Pleistoceno, com posterior migração para as Américas através da Beríngia (Hubbe et al., 2011)². Ou seja, similaridade craniana entre Paleoamericanos e africanos atuais não significa que houve uma passagem direta entre África e Américas.

Um outro grupo de pesquisadores tem proposto que os primeiros americanos, além de sua origem asiática, chegaram na América do Norte também vindo da Europa, cruzando o oceano Atlântico através de suas ilhas do extremo norte. A principal evidência dessa rota de migração são as semelhanças das pontas Clóvis, encontradas na América do Norte entre 13,4 e 12,7 mil anos (Miller et al., 2013), com os bifaciais da tradição Solutrense, existentes na Europa entre 25 e 16 mil anos (Bradley; Stanford, 2004; Stanford; Bradley, 2013). Outra evidência apontada pelos pesquisadores é a presença, mesmo que em baixa frequência, do haplogrupo mitocondrial $X$ em nativos americanos do nordeste da América do Norte, sendo este haplogrupo muito comum na população europeia atual (Perego et al., 2009; Oppenheimer et al., 2014). Porém, a ocorrência do haplogrupo $X$ em nativos americanos atuais não necessariamente correspondeu à sua distribuição no passado. $\bigcirc$ esqueleto de Kennewick, datado em 8,5 mil anos e encontrado no lado oposto, no noroeste da América do Norte, forneceu DNA mitocondrial antigo do haplogrupo $X$, sugerindo que a distribuição e a frequência desse haplogrupo no passado eram diferentes das atuais (Rasmussen et al., 2015). Além disso, as versões europeias desse haplogrupo, conhecidas como X2b, X2c e X2d, são diferentes da versão nativa americana, que é a versão exclusiva $\times 2$ a, e mais raramente a $X 2$ g. Essas formas exclusivas típicas das Américas poderiam ter vindo do Oriente Médio, que também possui o haplogrupo X2, e poderiam ter estado em baixa frequência no nordeste asiático, no momento da primeira entrada na América do Norte. Outro argumento que não corrobora a entrada nas Américas via Europa é que a data de origem do haplotipo exclusivo $X 2 a$ é semelhante à dos outros quatro haplogrupos principais em nativos americanos (A, B, C e D), os quais são tipicamente encontrados na Ásia, e não na Europa, sugerindo que os cinco haplogrupos possivelmente vieram em uma mesma migração (Raff; Bolnick, 2015). Os proponentes da migração via Europa propõem que a ocorrência em alta frequência do haplogrupo R1 do cromossomo Y no leste da América do Norte seria uma evidência adicional de conexão entre Europa e Américas (Oppenheimer et al., 2014). Todavia, outros autores defendem que o haplogrupo R1 encontrado em nativos americanos é resultado de miscigenação recente com europeus (Zegura et al., 2004).

Em síntese, há pesquisadores que defendem a entrada nas Américas via diversas rotas. Todavia, o pensamento majoritário dos pesquisadores da área é de que a evidência biológica aponta para uma origem asiática das populações ameríndias, e, integrada com evidências arqueológicas, sugere que a Beríngia foi a rota de entrada inicial para as Américas.

\section{DATA DA ENTRADA INICIAL NAS AMÉRICAS}

Os continentes americanos parecem ter sido as últimas grandes massas de terra a serem ocupadas pelo Homo sapiens, excetuando a Antártida. Há evidências arqueológicas de ocupação da Austrália há 65 mil anos (Clarkson et al., 2017), ao passo que até algumas décadas anteriores aceitava-se uma data de entrada nas Américas de apenas 14 mil anos (Fagan, 1990). O fato de as Américas serem os últimos continentes a serem habitados parece fazer sentido com a existência de uma massa de gelo na América do Norte durante parte do Pleistoceno, constituída pelas geleiras Laurentide e Cordilheira. De fato, o período conhecido como Último Máximo Glacial (UMG), ocorrido entre 28 a 18 mil anos atrás, foi caracterizado pela expansão dessas geleiras, fechando a rota de entrada por terra para a América do Norte (Hoffecker et al., 2014).

\footnotetext{
${ }^{2}$ Ver discussão nas seções a seguir.
}

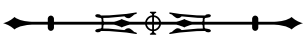


Nas últimas décadas, os métodos moleculares têm fornecido evidências consistentes sobre a data de entrada nas Américas. O método de coalescência é o que fornece os melhores resultados, permitindo a inferência do tempo de início da divergência das linhagens genéticas atuais (Harris, 2015). O tempo de coalescência do DNA mitocondrial e do cromossomo $\mathrm{Y}$ - ou seja, o momento em que as linhagens uniparentais atuais começaram a divergir - gira entre 35 a 10 mil anos atrás para os nativos americanos (Torroni et al., 1994; Bonatto; Salzano, 1997; Silva Júnior et al., 2002; Zegura et al., 2004; Achilli et al., 2008; Fagundes et al., 2008). Já os dados combinados mais recentes de DNA mitocondrial e DNA autossômico, extraídos de amostras atuais e arqueológicas, mostram que a idade de coalescência não é superior a 25 mil anos (Raghavan et al., 2015; Llamas et al., 2016). Os dados genéticos gerados por esses artigos têm mostrado que há uma série de trechos de DNA específicos dos nativos americanos espalhados por toda a América, sendo distintos do DNA encontrado em populações asiáticas. Junto com reconstruções paleoambientais, esses dados resultaram na formulação do Modelo da Permanência na Beríngia (MPB), que propõe que a colonização das Américas aconteceu nas seguintes etapas: primeiro, houve a ocupação da Beríngia por uma população asiática; segundo, houve um período de permanência na Beríngia, com ausência de troca gênica com a população asiática original, gerando os trechos de DNA exclusivos da população americana; por fim, houve uma rápida migração pelo continente americano após o UMG, quando o recuo das geleiras do extremo norte da América do Norte permitiu a entrada dessas populações nas Américas (Tamm et al., 2007). Cálculos recentes das datas absolutas desses eventos foram feitos usando DNA mitocondrial de amostras de populações atuais e arqueológicas. $\bigcirc$ isolamento completo da população ancestral dos nativos americanos na Beríngia ocorreu entre 24,9 e 18,4 mil anos atrás durante o UMG; o tempo de permanência na Beríngia foi de 9,0 a 2,4 mil anos; e a expansão dessa população para as Américas ocorreu entre
16 e 13 mil anos atrás. Essa expansão populacional a sul da Beríngia foi calculada como um aumento de 60 vezes, a partir de um tamanho efetivo de duas mil mulheres na Beríngia, ou seja, de poucas dezenas de milhares de pessoas. A fim de explicar achados arqueológicos em Monte Verde, no sul do Chile, datados de 14,6 mil anos atrás, acredita-se que houve uma migração rápida pela costa pacíica em um período máximo de 1,4 mil anos até o sul da América do Sul (Llamas et al., 2016). Análises de DNA mitocondrial dos haplotipos D1g e D1j, que só são encontrados em populações atuais do sul da América do Sul, resultaram em uma estimativa de coalescência entre 18 e 14 mil anos atrás, sugerindo chegada no extremo sul do continente por volta desse período (Bodner et al., 2012). Outra evidência genética do MPB é a existência de sinais de seleção positiva em genes dos ácidos graxos dessaturases (fatty acid desaturases genes - FADS), que apresentam uma versão exclusiva para as Américas espalhada por todo o continente. Essa adaptação é relacionada a uma dieta rica em proteínas, e provavelmente ocorreu no ambiente ártico da Beríngia (Amorim et al., 2017).

Dados paleoambientais mostram que o corredor de terra entre as geleiras da América do Norte ainda não estava aberto há 15 mil anos, sugerindo que a migração pela costa pacífica é a rota mais provável para a entrada nas Américas (Dixon, 2013). De fato, só há evidência de abertura desse corredor de terra por volta de 15 a 14 mil anos atrás. Ainda mais, só há evidência de animais e vegetação de tundra nesse corredor a partir de 12,6 mil anos, impedindo que, antes dessa data, o corredor tivesse sido uma rota viável para a entrada nas Américas (Pedersen et al., 2016). A rota pela costa pacífica pode ter sido feita por navegação de cabotagem, explorando uma mesma zona ecológica caracterizada por florestas de algas (kelp forests). Esse bioma é identificado por apresentar um ambiente de águas geladas com alta produtividade, constituído de linhas costeiras pedregosas que vão do Japão ao norte do México e depois voltam a aparecer no sul da América do Sul. As florestas de algas são ricas em

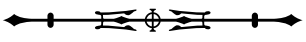


animais marinhos, pássaros, peixes e algas (Erlandson et al., 2007, 2015). As rotas costeiras e fluviais parecem ter sido os caminhos dessas primeiras ocupações, como é sugerido para o caso brasileiro, que, através do mapeamento de sítios Paleoíndios anteriores a 13 mil anos, mostrou que os grandes rios brasileiros eram locais preferenciais de assentamento (Bueno et al., 2013).

Embora o MPB e as suas datas associadas sejam bem aceitos pela maioria da comunidade científica, há limitações quanto ao método de coalescência, as quais precisam ser destacadas. A taxa de mutação é o ponto de maior debate, uma vez que vários métodos podem ser usados para o seu cálculo. Em um deles, chamado de filogenético, a taxa de mutação é calculada utilizandose um ponto de calibração fóssil conhecido, tal como a separação da linhagem dos orangotangos em relação aos outros hominídeos há 15 milhões de anos. Já no método direto, a taxa de mutação é calculada diretamente em populações humanas atuais, sendo depois assumido um tempo de geração de 20 a 30 anos para a extrapolação dessa taxa para o passado. Esses métodos têm gerado incerteza quanto aos números calculados. Além disso, há heterogeneidade das taxas de mutação nas diferentes linhagens e regiões do DNA (Scally; Durbin, 2012). Por outro lado, esse problema é intensificado somente quando as taxas de mutação são calculadas para DNA autossômico em linhagens de centenas de milhares de anos. Nesse sentido, as linhagens uniparentais são mais apropriadas para cálculos de coalescência, pois elas não sofrem efeitos de hibridização genética. Os métodos de coalescência em DNA mitocondrial são geralmente usados para linhagens mais recentes, uma vez que esse DNA apresenta particularmente alta taxa de mutação. Ainda assim, os marcadores uniparentais apresentam limitações pelo fato de representarem uma fração muito pequena da informação genética presente no organismo, além de sua transmissão ser restrita a somente uma linhagem, masculina ou feminina. Uma limitação mais geral do método de coalescência é a perda de linhagens ao longo da história genética de uma população. No caso dos nativos americanos, por exemplo, houve perda significativa de linhagens durante a colonização pelos europeus (Llamas et al., 2016), fazendo com que a incorporação de DNA antigo nessas análises, que é ainda incipiente, seja essencial para obtermos estimativa mais realista da data de coalescência das linhagens nativo-americanas.

Em face dessas limitações, a junção de múltiplas evidências bioarqueológicas é crucial para uma melhor inferência sobre a data inicial de entrada nas Américas. Nesse ponto, a existência de esqueletos humanos nos sítios antigos é uma evidência direta e indubitável da presença humana. Os esqueletos humanos mais antigos nas Américas datam, por métodos diretos e indiretos, de 14 a 12 mil anos atrás, como é o caso de dentes isolados escavados na serra da Capivara, no Piauí (Guidon et al., 2000), e dos esqueletos de Luzia, escavado em Lagoa Santa, em Minas Gerais (Neves et al., 1999b), de Hoyo Negro, escavado em Yucatan, no México (Chatters et al., 2014), e de Anzick-1, escavado em Montana, nos EUA (Becerra-Valdivia et al., 2018), entre outros. Essa idade mínima para a presença humana nas Américas é compatível com a evidência molecular aqui apresentada, em que a expansão das primeiras populações vindas da Beríngia ocorreu por volta de 16 mil anos atrás. $\bigcirc$ sítio postulado como o mais antigo das Américas, composto por líticos e ossos de fauna com marcas de corte, foi encontrado no extremo norte da América do Norte, na região do território de Yukon, nas cavernas de Bluefish, no Canadá, sendo datado em 24 mil anos (Bourgeon et al., 2017). Esse sítio parece representar a ocupação da Beríngia anterior à expansão populacional para as Américas. Por outro lado, o encontro de esqueletos humanos a sul da Beríngia nas Américas do Norte, Central e do Sul a partir de 14 mil anos atrás pode sugerir que, nesse momento, a densidade populacional no continente já tinha atingido um nível considerável, a ponto de gerar visibilidade arqueológica. Alguns arqueólogos sugerem que a presença humana é bem mais antiga nas Américas, porém os sítios que são

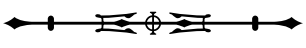


usados para sua sustentação são esparsos e não apresentam esqueletos humanos. De fato, há evidências arqueológicas, embora controversas, de sítios a sul da Beríngia datados em mais de 15 mil anos, tais como estratos profundos do sítio de Monte Verde, no Chile - datados entre 18,5 e 14,5 mil anos atrás (Dillehay et al., 2015) -, sítios localizados na serra da Capivara, no Piauí - datados de 20 mil anos atrás (Lahaye et al., 2013; Boëda et al., 2014) -, e do sítio Santa Elina, no Mato Grosso - datado de 27 mil anos atrás (Vialou et al., 2017) -, além disso, na Califórnia, há evidência de ossos de mastodontes com quebras típicas de osso fresco, associados com possíveis percutores em estratos datados de 130 mil anos atrás (Holen et al., 2017).

Essas datações arqueológicas antigas são alvo de sistemáticas críticas por parte da comunidade arqueológica. Os pesquisadores ressaltam dois pontos principais passíveis de análise: a associação das datações com o material arqueológico e a presença de artefatos e estruturas indubitavelmente produzidas por humanos (Fiedel, 2000). questionamento às datações antigas dos sítios da serra da Capivara, Piauí, por exemplo, consistiu principalmente no questionamento da origem antrópica das fogueiras e dos instrumentos líticos encontrados na região (Meltzer et al., 1994). Evidências arqueológicas muito antigas, como as encontradas na Califórnia há 130 mil anos, têm sido criticadas menos pela precisão das datações e mais pela fragilidade da evidência de atividade humana naquele sítio (Braje et al., 2017).

Ainda assim, há outras evidências arqueológicas que também contestam a cronologia do MPB. Montenegro et al. (2006) constataram que coprólitos humanos, que datam de até 9 mil anos atrás na América do Sul, mostram a presença de um pacote de parasitas compostos por Ancylostoma duodenale, Trichuris trichiura e Strongyloides stercoralis. Esses parasitas só sobrevivem em ambientes com alta umidade e calor, uma vez que seu ciclo de vida é dependente de condições específicas do solo. Dessa forma, os autores propõem uma migração antiga para as Américas que evolveu caminho costeiro ou migração transoceânica, sem permanência em um local frio e seco, como a Beríngia. $O$ achado desses parasitas em datas ainda mais antigas nas Américas poderia corroborar esse questionamento à cronologia estabelecida pelo MPB.

Em síntese, evidências genéticas e arqueológicas têm feito com que o MPB seja a explicação mais aceita para a ocupação das Américas, sendo que a data de expansão da Beríngia não é anterior a 16 mil anos. Por outro lado, devido às limitações dos métodos genéticos e a alguns achados arqueológicos esparsos e ainda controversos, há pesquisadores que defendem ocupações mais antigas do que as propostas pelos geneticistas. Novos dados arqueológicos ainda precisam ser obtidos para esclarecer completamente a data de entrada inicial nas Américas.

\section{NÚMERO DE MIGRAÇÕES PARA AS AMÉRICAS}

O número de ondas migratórias é o assunto de maior controvérsia nos modelos de ocupação das Américas. O debate sobre o número de migrações já existia desde o século XIX, sob a forma de discussões sobre heterogeneidade biológica dos nativos americanos. Alguns pesquisadores defendiam a homogeneidade das populações americanas ${ }^{3}$, ao passo que outros defendiam uma heterogeneidade biológica associada a diversas migrações para o continente ${ }^{4}$. Um modelo específico para tratar do número de migrações foi publicado por Greenberg et al. (1986), usando dados linguísticos, traços não métricos de dente e polimorfismos de DNA. Esse modelo foi denominado de Modelo das Três Migrações (MTM). Ele preconizava que três grupos distintos entraram nas Américas: ameríndios, esquimós-aleutas e na-dene, sendo que os dois últimos foram migrações restritas ao extremo norte da América do Norte.

\footnotetext{
3 Ver Hrdlička (1912).

4 Ver Rivet (1957).
}

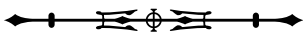


Desde a publicação do MTM, os métodos genéticos foram os que mais forneceram evidências empíricas para os modelos de ocupação das Américas. Durante a década de 1990, um modelo aqui denominado de Modelo da Migração Única (MMU) ganhou força entre os pesquisadores, utilizando-se de métodos de coalescência a partir do sequenciamento de DNA mitocondrial de nativos americanos (Schurr, 2005). Esses estudos mostraram que os haplotipos exclusivos de nativos americanos, a dizer, A2, B2, C1b, C1c, C1d, e $\mathrm{D} 1$, se originaram ao mesmo tempo e estavam, a grosso modo, distribuídos por todo o continente. Torroni et al. (1993) chegaram a propor que o haplogrupo B entrou nas Américas através de uma migração mais recente, porém essa proposição foi criticada, devido à existência de uma expansão recente do haplogrupo $B$, associada a populações agrícolas do sudoeste norte-americano, enviesando os resultados. Em síntese, o conjunto da evidência genética apontava àquela época para uma migração única baseada no DNA mitocondrial (Merriwether et al., 1995; Bonatto; Salzano, 1997; Fagundes et al., 2008) e no cromossomo Y (Zegura et al., 2004).

Os modelos genéticos ganharam ainda mais robustez quando dados de DNA autossômico foram incorporados nos modelos de ocupação. O DNA autossômico de 163 nativos americanos advindos de 34 populações espalhadas pelas Américas foi estudado por Reich et al. (2012). Esse estudo identificou uma migração única inicial, que ocupou todo o continente, e duas migrações árticas posteriores, a que gerou os esquimós-aleutas, que tiveram $43 \%$ do seu DNA oriundo da segunda migração, e a que gerou os nadene, que tiveram 10\% de seu DNA oriundo da terceira migração. As populações da América do Sul se estruturaram logo após a primeira grande migração e tiveram pouco fluxo gênico desde então. Além disso, foi observada uma relativa separação genética entre América do Norte e do Sul, provavelmente devido à restrita troca gênica entre essas populações. Foi observada também uma relação entre troncos linguísticos e a estruturação do DNA autossômico. Esses resultados, junto com alguns estudos de morfologia craniana (González-José et al., 2008; De Azevedo et al., 2011, 2017)5, serão agrupados no que é aqui denominado de Modelo de Fluxo Gênico Recorrente (MFGR). O MFGR propõe uma migração única para as Américas do Norte, Central e do Sul, mas reconhece que houve migrações adicionais posteriores na região circum-ártica. Esse modelo recupera alguns elementos originais do MTM proposto na década de 1980, porém, dessa vez, com evidências de hibridização entre populações na região ártica.

O sequenciamento de DNA autossômico permitiu o estudo de episódios de mistura gênica entre populações. Um conjunto de estudos recentes nesse tema, baseado em DNA de 110 indivíduos nativos da Ásia, das Américas, da Sibéria e da Oceania, além de 23 genomas antigos de esqueletos da América do Norte e do Sul datados de 6,0 a 0,2 mil anos atrás, mostrou que a primeira migração para as Américas consistiu das levas biológicas de ameríndios e na-dene, ao passo que uma segunda migração posterior compôs a população inuit. Esse modelo, portanto, propõe duas migrações constituídas de três levas biológicas. Além disso, esses estudos mostraram a existência de mistura gênica na Ásia anterior à entrada da primeira migração nas Américas. O esqueleto de Mal'ta, encontrado na Sibéria e datado em 24 mil anos atrás, apresentou cerca de 14 a 28\% de semelhança no DNA autossômico com as populações nativas americanas, provavelmente devido à sua troca gênica com populações ancestrais dos nativos americanos antes da diferenciação na Beríngia. Essa mesma população de Mal'ta é também ancestral de populações atuais do oeste da Europa (Raghavan et al., 2014, 2015). Além disso, foi detectada mistura gênica da leva biológica dos inuit com a dos na-dene e de migração reversa de populações americanas para o nordeste da Ásia depois da colonização das Américas (Raghavan et al., 2015).

\footnotetext{
5 Ver discussão a seguir.
}

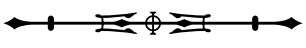


Esse refinamento do entendimento da dinâmica de populações antigas é muito devido às novas técnicas de sequenciamento em larga escala de DNA autossômico atual e antigo. O DNA antigo, em especial, tem gerado as maiores contribuições para os modelos de migração e de fluxo gênico. A principal limitação técnica para a extração de DNA antigo era a extrema fragmentação do DNA em trechos de 50 a 150 pares de bases no material fóssil. Além disso, para o sequenciamento de DNA antigo, é necessária a abertura das cadeias duplas fitas (desnaturação) e posterior amplificação e sequenciamento em larga escala. Esse processo demanda tempo, dinheiro e conhecimento bioinformático. Posteriormente, é preciso eliminar a contaminação de DNA de bactérias, pois menos de $1 \%$ do material genético antigo nos ossos é humano. $O$ desenvolvimento de equipamentos de sequenciamento e a construção de laboratórios superesterilizados exclusivos para a extração de DNA antigo têm contribuído para o progresso de pesquisas nesta área. Ainda assim, um trabalho extenso de bioinformática é necessário para conectar os fragmentos de DNA, resultando em coberturas muito menores do que a usual cobertura de 30 vezes obtida em DNA modernos. De todo modo, os avanços técnicos e computacionais das últimas décadas possibilitaram que esses estudos passassem a ter grande impacto e ser mais comuns na literatura bioantropológica (Pääbo, 2014).

Nos últimos dez anos, diversos estudos foram publicados descrevendo sequências genéticas de esqueletos humanos em contexto arqueológico nas Américas. $O$ caso do esqueleto de Anzick-1, em Montana, nos EUA, datado em 12,8 mil anos atrás e provavelmente pertencente à cultura Clovis é particularmente relevante. $O$ esqueleto teve seu DNA mitocondrial (tipo D4h3a) e autossômico sequenciado. Esses dados mostraram maior similaridade desse indivíduo com ameríndios da América Central e do Sul. Este estudo mostra que indivíduos da cultura Clóvis tiveram uma conexão biológica com os nativos da América do Sul (Rasmussen et al., 2014). Já o DNA mitocondrial de remanescentes esqueletais da costa noroeste dos EUA, provavelmente pertencentes ao povo na-dene, mostrou uma descontinuidade genética por volta de 6 mil anos atrás, quando o haplotipo D4h3a foi substituído pelo A2. A evidência mais antiga nessa região é o esqueleto de Sukaá Káa, datado de 10,3 mil anos atrás na costa do Alasca. Embora haja descontinuidade do DNA mitocondrial, os pesquisadores propõem que não necessariamente houve uma descontinuidade populacional, já que a amostra de esqueletos sequenciada é ainda muito pequena. A linhagem A2, por exemplo, que já fazia parte da população colonizadora das Américas, provavelmente será também encontrada nos primeiros habitantes da América do Norte. Além disso, as análises do DNA autossômico desses mesmos esqueletos mostraram continuidade genética entre as populações da região, diferindo da sequência encontrada no esqueleto de Anzick-1, que tem DNA autossômico similar ao de populações da América Central e do Sul (Lindo et al., 2017). Já o esqueleto de Kennewick, datado em 8,5 mil anos atrás, e encontrado no noroeste dos EUA, porém no interior do continente, apresentou DNA mitocondrial do tipo X2a, que é encontrado em populações atuais do nordeste americano. Essa ocorrência do haplogrupo X em local diferente da distribuição atual do haplogrupo mostra um pouco dos deslocamentos populacionais ocorridos na América do Norte ao longo do Holoceno. Por outro lado, - DNA autossômico desse esqueleto mostrou conexão genética com os habitantes atuais do noroeste americano, indicando algum grau de continuidade biológica na região nos últimos 8 mil anos (Rasmussen et al., 2015). Esses exemplos evidenciam a importância do sequenciamento de DNA antigo para refinar os modelos demográficos de ocupação das Américas.

Em termos de aderência aos modelos correntes de ocupação das Américas, os dados de DNA antigo sustentam, em sua grande maioria, o MFGR e o MPB. Nesse aspecto, eles apontam que, com exceção das regiões árticas ocupadas pelos na-dene e pelos esquimós-aleutas, houve apenas uma migração, oriunda de uma população efetiva pequena que se diferenciou geneticamente na Beríngia. A análise de 
DNA mitocondrial antigo de 92 esqueletos pré-colombianos na América do Sul datados entre 8,6 e 0,5 mil anos atrás mostrou a presença dos quatro haplogrupos principais encontrados nas Américas ( $A, B, C$ e D), corroborando a origem única dessas populações ameríndias. Por outro lado, foram encontrados 84 haplotipos mitocondriais diferentes de populações nativas americanas atuais, mostrando uma substancial perda de material genético com a chegada de europeus na América do Sul. No entanto, esses resultados não contradizem a origem única dos ameríndios a partir de uma população da Beríngia. A estrutura genética na América do Sul, oriunda de uma população única e bastante variada, foi atingida logo no início da ocupação do continente, e depois houve pouco fluxo gênico entre elas (Llamas et al., 2016). Uma outra análise corroborando o modelo de origem única para os ameríndios é o sequenciamento do DNA de dois esqueletos datados de 11,5 mil anos e escavados no sítio Upward Sun River, no Alasca. Os haplotipos mitocondriais encontrados foram o C1 e o B2, e a análise de DNA autossômico, com uma boa cobertura de 17 vezes, indicou que esses indivíduos são provavelmente descendentes da população original da Beríngia, que está na base de toda a diversificação dos ameríndios atuais (Moreno-Mayar et al., 2018a). Reunindo informações de sequenciamento do DNA autossômico de várias dezenas de indivíduos arqueológicos, novos estudos têm detalhado a histórica genética dos nativos americanos, mostrando a complexidade de interações e deslocamentos ocorridos dentro das Américas (MorenoMayar et al., 2018b; Posth et al., 2018; Scheib et al., 2018). Todavia, esses estudos continuam a sustentar uma origem comum recente para os nativos americanos, que foram geneticamente separados da população asiática após 25 mil anos. Em síntese, as evidências genéticas apontam para o modelo de que, a sul da zona ártica, a ocupação das Américas foi derivada de uma população única.

Um segundo grande grupo de estudos biológicos sobre modelos de migrações para as Américas é o estudo morfológico de crânios e dentes. Embora haja um crescente reconhecimento de que o DNA é uma ferramenta mais poderosa para a inferência de filogenia e demografia antiga (Harris, 2015), a escassez de material genético antigo nos fósseis ainda é um fator limitante para maiores inferências sobre o tema. Populações antigas que não deixaram descendentes atuais podem enviesar os modelos de ocupação do continente advindos da genética. Nesse ponto, os fósseis ainda são cruciais para a inferência de dinâmicas populacionais no passado. Um dos modelos de ocupação das Américas baseado em traços craniométricos é o Modelo dos Dois Componentes Biológicos Principais (MDCBP), que ainda exerce grande influência em âmbito internacional (Hubbe; Neves, 2017), o qual foi formulado por Neves et al. (1999a, 1999b, 2003, 2005, 2007, 2013), e propõe que duas levas biológicas chegaram às Américas em momentos distintos. A primeira delas chegou em algum momento antes de 13 mil anos atrás e é chamada de paleoamericana, enquanto a segunda leva biológica chegou após 13 mil anos e é denominada de ameríndia, sendo esta última, ao substituir a primeira, a principal contribuidora das populações nativas americanas atuais. Os paleoamericanos são caracterizados por apresentar crânios estreitos e longos, faces baixas e prognatas, e órbitas e cavidades nasais relativamente largas e baixas. Já os ameríndios têm crânios curtos e largos, faces altas, largas e ortognatas, e cavidades nasais e órbitas relativamente altas e estreitas. Estudos craniométricos comparando as populações de paleoamericanos de Lagoa Santa, no Brasil, e Sabana de Bogotá, na Colômbia, com populações mundiais do banco de dados Howells (Neves; Hubbe, 2005) e Hanihara (Bernardo, 2007) mostraram que os paleoamericanos são morfologicamente mais próximos de populações modernas da África e da Australo-Melanésia, ao passo que os ameríndios são mais próximos de populações asiáticas. O MDCBP propõe, então, que houve duas migrações para a América e que a segunda substituiu a primeira, sendo que ambas as morfologias já eram distintas antes de entrarem nas Américas (Neves; Hubbe, 2005). Para dar robustez a esse modelo, além dos 88 crânios medidos em Lagoa Santa (Neves; Hubbe, 2005; Neves et al., 2014),

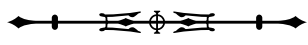


amostras esqueletais datadas em mais de 7 mil anos atrás foram medidas em Palli Aike, no sul do Chile (Neves et al., 1999a), na Argentina (Pucciarelli et al., 2010), nos crânios Umbú do sul do Brasil (Neves et al., 2004), no sambaqui fluvial de Capelinha, em São Paulo (Neves et al., 2005), na Toca das Onças, no sul da Bahia (Hubbe et al., 2004), na serra da Capivara, no Piauí (Hubbe et al., 2007), na Sabana de Bogotá, na Colômbia (Neves et al., 2007; Delgado, 2017), no México (González-José et al., 2005) e na América do Norte (Jantz; Owsley, 2001). Em todos esses locais, paleoamericanos apresentaram morfologia diferente de nativos americanos atuais. O MDCBP explica a presença de morfologia africana e australo-melanésica nas Américas pelo fato de a morfologia generalizada africana estar presente por todo o Velho Mundo durante o final do Pleistoceno, enquanto a morfologia craniana asiática, similar à de nativos americanos atuais e denominada de mongoloide, só apareceu posteriormente como uma adaptação local na Ásia (Hubbe et al., 2011). Ainda mais, o modelo considera que a entrada das duas levas biológicas nas Américas se deu através do Estreito de Bering.

Estudos testando o MDCBP continuaram gerando novos dados na última década, seja através de novas abordagens estatísticas, seja através de novos métodos de registro da morfologia craniana. $\bigcirc$ uso de modelos de diferenciação geográfica e temporal, que assumem uma taxa de mudança baseada em modelos evolutivos neutros, corroboraram estatisticamente a ideia de que as duas migrações explicam melhor a variação craniana nas Américas do que uma migração única seguida de diferenciação craniana in situ (Hubbe et al., 2010, 2014). Uma análise usando morfometria geométrica 3D, modelos de distância geográfica e genética populacional apontou também para o MDCBP como a explicação mais parcimoniosa para a diversidade craniana encontrada nas Américas, acrescentando que a morfologia da face dos paleoamericanos é a mais similar a uma morfologia ancestral generalizada, que teve origem na África (Cramon-Taubadel et al., 2017). Embora a diferença entre as morfologias paleoamericana e ameríndia seja evidente em algumas populações, há exemplos de populações recentes com sobrevivência tardia da morfologia paleoamericana. Os exemplos reportados na literatura são os fueguinos do extremo sul da América do Sul (Lahr, 1995; Turbon et al., 2017), os pericus da Baja California, na América do Norte (González-José et al., 2003), e os botocudos do Brasil central (Strauss et al., 2015a). Segundo o MDCBP, essas populações seriam a sobrevivência tardia do primeiro componente biológico que entrou nas Américas, mostrando que houve, de fato, substituição apenas parcial do primeiro pelo segundo componente biológico.

Os dados genéticos, em sua grande maioria, não fornecem suporte ao MDCBP. A coleção de crânios de botocudos do Brasil central, considerados como uma sobrevivência tardia da morfologia paleoamericana, apresentou, em sua maioria, DNA mitocondrial típico de populações nativas americanas modernas, a dizer, 12 indivíduos com haplogrupo C1. Por outro lado, dois indivíduos botocudos apresentaram DNA mitocondrial B4a1a1, que é um haplotipo típico de indivíduos polinésios recentes (Gonçalves et al., 2010, 2013). Esses dois indivíduos foram datados entre 1479 e 1842 d.C., e seus DNA autossômicos confirmaram a ligação com a Polinésia, especialmente com a Ilha de Páscoa, não contendo qualquer mistura genética com nativos americanos (Malaspinas et al., 2014). Nessa mesma linha de contato entre Polinésia e América do Sul, DNA autossômico de indivíduos Suruí e Karitiana, da Amazônia, e Xavante, do Brasil central, apresentou conexão genética com indivíduos australoasiáticos (Skoglund et al., 2015). No sentido inverso, análise de DNA autossômico de indivíduos da llha de Páscoa mostrou que houve hibridização com nativos americanos entre 1280 e 1425 d.C., inserindo cerca de 8\% de DNA ameríndio em moradores dessa ilha (Moreno-Mayar et al., 2014). Embora esse contato entre Polinésia e América do Sul pudesse sugerir uma evidência genética do primeiro componente biológico paleoamericano, foi encontrado um componente genético australo-melanésio também

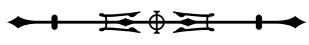


nos aleutas da América do Norte, abrindo a possibilidade de ter havido, de fato, uma migração australo-asiática relativamente recente pelo nordeste da Ásia para as Américas. Somado a isso, o DNA autossômico de pericus e fueguinos, considerados como detentores da morfologia paleoamericana, não mostrou qualquer diferença genética em relação aos nativos americanos atuais, contradizendo o MDCBP (Raghavan et al., 2015). O DNA autossômico do homem de Kennewick, datado em 8,5 mil anos e que apresenta uma morfologia craniana similar aos ainu e aos polinésios, também mostrou similaridades genéticas com populações ameríndias recentes (Rasmussen et al., 2015). Na península de Yucatan, no México, o crânio de Hoyo Negro, datado entre 12 a 13 mil anos, e que apresenta morfologia paleoamericana ${ }^{6}$, evidenciou DNA mitocondrial do haplogrupo D1, que ocorre em 10,5\% dos nativos americanos atuais (Chatters et al., 2014). Por sua vez, Moreno-Mayar et al. (2018b) encontraram uma fração pequena de DNA autossômico australo-melanésico na população paleoamericana de Lagoa Santa, porém esse sinal genético está ausente nos esqueletos norte-americanos antigos, sequenciados até o momento, incluindo o crânio com morfologia paleoamericana de Spirit Cave, em Nevada. Em síntese, o conjunto da evidência genética não corrobora o MDCBP. Por outro lado, Posth et al. (2018) detectaram ao menos três expansões populacionais antigas para a América do Sul, sendo que uma delas, ocorrida após 9 mil anos, substituiu amplamente a população pioneira na região, incluindo os paleoamericanos de Lagoa Santa. Assim, os defensores do MDCBP podem, ao menos, argumentar que os dados genéticos da América do Sul corroboram a existência de um episódio amplo de substituição populacional no continente. Esses dados parecem apontar para um modelo mais complexo, que inclui múltiplos movimentos populacionais e episódios de hibridização dentro das Américas, incluindo um componente australomelanésio antigo, que ainda não tem origem bem definida.
À luz das críticas oriundas dos dados genéticos ao MDCBP, outros modelos de ocupação das Américas têm sido propostos com base nos dados craniométricos. Um dos esforços mais robustos para compatibilizar dados genéticos com morfológicos foi realizado por um grupo de brasileiros e argentinos através de métodos de morfometria geométrica. Em uma reinterpretação dos dados craniométricos, Rolando González-José e colegas propuseram que as morfologias cranianas antiga e recente estão dentro de um espectro único de variação biológica nas Américas. Ao invés de duas levas distintas, a população original, oriunda da Beríngia, era bastante variada, incluindo gradações entre as morfologias paleoamericana e ameríndia. Além disso, a população nativa americana atual manteve essa alta variabilidade morfológica, considerando a sobrevivência tardia da morfologia paleoamericana como, na verdade, apenas um extremo dessa alta variabilidade. Essa interpretação da evidência morfológica, junto com os dados genéticos aqui citados, é a base de sustentação do MFGR (González-José et al., 2008; De Azevedo et al., 2011, 2017). A crítica dos defensores do MDCBP é que a variação craniométrica antiga, medida através do coeficiente de variação, é baixa na América do Sul, considerando-se as duas maiores coleções de crânios da América do Sul, a dizer, Lagoa Santa, no Brasil, e Sabana de Bogotá, na Colômbia (Hubbe et al., 2015). Porém, devido à escassez de coleções antigas nas Américas, essa análise só foi feita para duas populações. Incorporando crânios de várias localidades do oeste da América do Sul, não parece haver uma clara distinção entre Holoceno inicial e final nessa região (Kuzminsky et al., 2017). Por exemplo, os crânios de Lauricocha, no Peru, apresentam continuidade morfológica e genética com populações atuais (Fehren-Schmitz et al., 2015). Já no Chile, a evidência é mista. Dois crânios antigos mostram similaridades com populações recentes, ao passo que outros dois crânios antigos mostram descontinuidades, embora todos possam

\footnotetext{
6 Ver opinião contrária em De Azevedo et al. (2015).
}

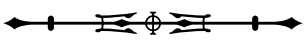


ser incluídos no espectro de variação de populações nativas atuais (Kuzminsky et al., 2018). De fato, quatro crânios são uma amostra pequena para se fazer inferências populacionais. Outros autores observaram similaridades entre crânios paleoamericanos com os habitantes antigos do Japão e com crânios do Arcaico norte-americano, mostrando uma continuidade entre populações antigas e recentes (Seguchi et al., 2011). Porém, essas análises só utilizaram cinco crânios antigos de Lagoa Santa.

É importante notar que existem limitações intrínsecas aos estudos de morfologia craniana para inferir história populacional. Devor (1987) calculou que a herdabilidade do crânio varia de 48 a 61\%, reconhecendo que existe um fator ambiental considerável na morfologia craniana adulta. Outros processos também são passíveis de ser detectados nos crânios, como adaptação morfológica à temperatura por seleção natural ou plasticidade fenotípica. De fato, adaptações ao frio influenciam na morfologia craniana, como foi descrito para os inuit, da Groelândia, e os buriat, da Rússia, que apresentam convergência morfológica sem tanta proximidade filogenética (Relethford, 2010). Outros pesquisadores também observaram o efeito da seleção natural nos traços do crânio e do nariz em ambientes frios, tal como nas populações da Sibéria (Roseman, 2004; Harvati; Weaver, 2006; Hubbe et al., 2009). Além disso, o módulo mastigatório do crânio é sensível à carga mecânica (González-José et al., 2004). A mandíbula, por exemplo, é sensível à mastigação, apresentando formato mais estreito e longo em caçadores-coletores e mais curto e largo em agricultores, explicando muito do apinhamento de dentes em populações agricultoras mais recentes (Cramon-Taubadel, 2011). No caso de populações nativas americanas, dieta, temperatura e subsistência são aventadas como fatores modificadores do tamanho e da forma craniana (Perez; Monteiro, 2009; Perez et al., 2011; Menéndez et al., 2014). Esses fatores ambientais sugerem modificação in situ de populações nativas americanas. Os estudos aqui citados indicam que sinais de seleção natural em partes do crânio de populações árticas são a razão de sua distinção morfológica em relação ao restante dos nativos americanos. Além disso, há a possibilidade de que deriva genética esteja atuando em populações isoladas, como os pericues, no Novo México, mostrando que múltiplas forças podem ter influenciado na variação morfológica nas Américas (Galland; Friess, 2016). Os pesquisadores que estudam crânios para inferir padrões de movimentação populacional argumentam que, ainda que seja notável a ação de fatores ambientais em algumas partes da morfologia craniana, tais como o módulo mastigatório, o crânio como um todo ainda reflete a divergência histórico-genética, já que seus módulos variam de forma correlacionada, fenômeno esse chamado de integração morfológica (González-José et al., 2004). Reforçando este ponto, Relethford (2002) aplicou análise de variância nos traços craniométricos humanos e constatou que o modelo neutro de genética de populações se aplica também aos crânios, reforçando a ideia de que, embora de modo imperfeito, modelos neutros de genética de populações podem ser aplicados no estudo de história populacional usando crânios, ou seja, o crânio reflete, em alguma medida, a história populacional (Manica et al., 2007). No caso da ocupação das Américas, os defensores do MDCBP argumentam que seria muito improvável que processos in situ produzissem por si só uma morfologia ameríndia tão semelhante à morfologia mongoloide presente na Ásia (Neves; Hubbe, 2005). Em síntese, embora haja estudos que embasem o uso da craniometria para entender movimentos populacionais no passado, é notório que há outros fatores atuando na morfologia adulta, tais como questões ambientais agindo durante o desenvolvimento ósseo.

Em vista das limitações dos estudos craniométricos aqui citados, a morfologia dentária surge como forma alternativa de testar modelos de ocupação do continente. Os dentes têm relativamente maior correspondência com fatores genéticos, variando entre 60 a 90\% de herdabilidade, sendo muito menos plásticos durante o desenvolvimento (Scott; Turner II, 1997; Townsend et al., 2009). Infelizmente, os estudos com dentes dos primeiros americanos são

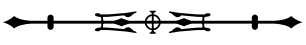


escassos, o que é devido, em parte, ao número amostral baixo de dentes antigos, mas principalmente pelo alto grau de desgaste dentário de populações caçadorascoletoras, impedindo a visualização e a medição dos dentes (Stojanowski; Johnson, 2015). Ainda assim, estudos pontuais mostraram que os dentes de paleoamericanos são diferentes dos de nativos americanos atuais usando tanto traços não métricos (Powell, 2005) como traços métricos (Nunes, 2010). Neste último trabalho, a comparação de dados de paleoamericanos com o banco Hanihara de dados dentários mundiais mostrou a associação dos dentes antigos de Lagoa Santa, Brasil, com os da Polinésia e com o sudeste asiático, corroborando os estudos craniométricos na região. A diferença entre paleoamericanos e ameríndios também foi observada nos dentes de coleções esqueletais do Chile e do Peru, como previsto pelo MDCBP (Sutter, 2005). Já outros estudos utilizando traços não métricos não corroboram o MDCBP, mostrando, ao invés, uma continuidade entre populações paleoamericanas e ameríndias. Utilizando o banco de dados mundial de traços não métricos de Turner, Scott et al. (2018) mostraram que é mais parcimonioso explicar a variação dentária nas Américas através de uma população original única com morfologia sinodonte. Essa população desenvolveu uma variação morfológica sinodonte exclusiva na Beríngia e, por fim, expandiu para as Américas. Porém, é importante notar que as amostras são pequenas e as populações sul-americanas, com especial ênfase aos esqueletos de Lagoa Santa, são muito pouco representadas nesse banco de dados. Um outro estudo com traços não métricos de dentes, focando, por sua vez, em amostras sul-americanas, também não corroborou integralmente o MDCBP. Huffman (2014) mostrou que há populações na América do Sul que apresentam padrão sundadonte, que é um padrão asiático ancestral e hoje é encontrado no sudeste asiático. Há, no entanto, outras populações que apresentam padrão sinodonte, e outras ainda apresentam um padrão que não se adequa a nenhum dos dois tipos. Embora essa variação seja esperada segundo o MDCBP, a morfologia craniana não está correlacionada perfeitamente com os traços não métricos dos dentes. Por exemplo, as populações antigas de Lagoa Santa, as de sambaquis do Holoceno Médio e as recentes de botocudos apresentaram todas um padrão sundadonte, sugerindo uma continuidade biológica ao longo do Holoceno no Brasil. Em síntese, os estudos com morfologia dentária apresentaram resultados conflitantes, que não se adequam de forma incontestável a nenhum dos modelos propostos até então.

O panorama sintético dessas múltiplas evidências é de que não há um consenso sobre quantas levas migratórias entraram nas Américas. O MFGR e o MPB, oriundos dos dados genéticos, são os mais aceitos atualmente, devido ao impacto científico da área genética nas últimas décadas, o que tem gerado enorme quantidade de dados relevantes para responder questões de história populacional. Esses modelos defendem uma migração única para as Américas, com exceção de migrações posteriores na região ártica. A força do modelo genético tem feito com que interpretações da morfologia craniana, que se ajustam a essa migração única, tenham ganhado força. Por outro lado, embora mais marginalizados, o MDCBP e os modelos de mudança ambiental in situ ainda mantêm seus adeptos, já que os dados genéticos ainda não são capazes de explicar os padrões morfológicos observados nos crânios. Modelos complexos, que expliquem sinais genéticos e morfológicos australoasiáticos nas Américas e que unam fatores ambientais e genético-históricos, ainda estão para ser formulados.

\section{SUBSISTÊNCIA E RITUAIS MORTUÁRIOS DOS PRIMEIROS AMERICANOS}

As pesquisas sobre primeiros americanos têm sido centradas na origem biológica e na antiguidade de entrada nas Américas. Por outro lado, pouco se discute sobre o entendimento do modo de vida dessas primeiras populações. Em grande medida, isso é devido à complexidade da reconstrução do modo de vida de populações do passado, ainda mais quando há escassez de evidências arqueológicas. A fim de inserir esse importante tópico na discussão sobre os primeiros americanos, irei traçar, de forma breve, um panorama de

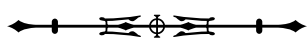


quais são as evidências biológicas sobre o estilo de vida das populações antigas das Américas, focando nos rituais mortuários e na subsistência.

Os rituais mortuários são centrais para o entendimento do universo simbólico de populações humanas. Eles refletem tanto o conjunto de práticas funerárias de uma população como a sua organização social (Parker Pearson, 1999). Na América do Norte, remanescentes ósseos humanos de populações pleistocênicas são raros e esparsos, limitando nosso entendimento sobre práticas funerárias a poucos casos isolados. $\bigcirc$ esqueleto de Anzick-1, atribuído à cultura Clovis e datado em 12,8 mil anos atrás, foi enterrado junto com líticos e artefatos ósseos e presença de ocre vermelho (Becerra-Valdivia et al., 2018). Já o esqueleto de Buhl, encontrado em Idaho, nos EUA, e datado em 12,6 mil anos atrás, apresentou acompanhamento funerário composto por um bifacial com pedúnculo, uma agulha e um furador de osso com incisões (Green et al., 1998). Outro sepultamento isolado com dois esqueletos fletidos (uma mulher subadulta e um homem adulto) é o de Horn Shelter 2, no Texas, datado em cerca de 11,1 mil anos atrás. Esse sepultamento incluiu acompanhamento funerário composto por ocre, contas de conchas, ossos e dentes de animais e instrumentos bifaciais (Jodry; Owsley, 2014). No extremo norte das Américas, no sítio Upward Sun River, Alasca, foi datado em 11,5 mil anos atrás um enterramento com dois esqueletos de crianças, com acompanhamento funerário com bifaces e chifres decorados. Além disso, um segundo enterramento com uma criança cremada foi encontrado junto com o primeiro em uma estrutura residencial (Potter et al., 2014). Já o sítio Sloan, em Arkansas, nos EUA, datado entre 12 e 12,5 mil anos atrás, é uma exceção ao quadro descrito anteriormente, pois apresenta concentração significativa de remanescentes ósseos humanos antigos. Esse sítio foi caracterizado como um sítio-cemitério, pois apresentou 29 grupos de fragmentos ósseos humanos associados a concentrações de artefatos e a ocre vermelho e amarelo. Esses ossos humanos estavam espalhados por uma área de 144 metros quadrados (Morse, 1997). Os líticos associados com os ossos humanos eram, em parte, de uso cotidiano e, em parte, voltados para fins rituais, incluindo pontas bifaciais grandes com poucas marcas de uso. A diferenciação desses acompanhamentos funerários por sexo e idade dos indivíduos parece ter sido mínima (Smallwood et al., 2018). Olhando para o conjunto da evidência, esses achados apontam para uma variabilidade dos rituais mortuários nesse período, mesmo considerando a variabilidade dentro de populações particulares, como as do Alasca.

Na América do Sul, a região de Lagoa Santa, em Minas Gerais, apresentou alta diversidade de rituais mortuários ocorridos em uma população que enterrou seus mortos entre 10,5 e 8 mil anos atrás. No sítio Lapa do Santo, por exemplo, há casos de decapitação, cremação, ossos longos cortados, enterramentos múltiplos, uso de ocre, fardo de ossos e quebras frescas em 26 sepultamentos. Esses enterramentos sugerem manipulação intensa dos ossos, embora não apresentem acompanhamentos funerários (Strauss, et al., 2015b, 2016). Alguns sepultamentos isolados também são encontrados na América do Sul, tais como um esqueleto de mulher adulta no sítio Sueva, da Colômbia, com datação de cerca de 11,6 mil anos atrás. Esse esqueleto estava associado com ossos de fauna, ocre vermelho e instrumentos líticos (Correal Urrego, 1979). No sítio Jaywamachay, no Peru, foram encontrados sepultamentos de um adulto com ossos depositados em fardo e uma criança com o crânio queimado, datados entre 11 e 9 mil anos (MacNeish et al., 1983). Já no sítio Justino, no cemitério mais antigo, datado em cerca de 10 mil anos, foram encontrados cinco sepultamentos e duas concentrações de ossos, apresentando acompanhamentos funerários de pedras lascadas, sem distinção de elaboração entre eles (Vergne, 2007). De fato, há poucos esqueletos antigos descritos em detalhe para a América do Sul ${ }^{7}$.

\footnotetext{
7 Ver revisões em Santoro et al. (2005) e Strauss (2014).
}

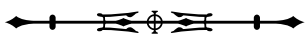


Esses autores sugerem que os rituais mortuários nos habitantes antigos das Américas apresentaram uma diversidade de formas, incluindo manipulação do corpo, cremação, uso de ocre e acompanhamentos funerários, além de esqueletos enterrados de forma primária. Esses esqueletos eram enterrados tanto em sítios-moradias como em locais especiais. Por sua vez, fica claro que a visibilidade desses esqueletos é pequena antes de 12 mil anos, sendo que locais com acumulação de esqueletos começam a aparecer somente no início do Holoceno no sudeste norte-americano e em Lagoa Santa, no Brasil. Essa acumulação maior de esqueletos pode ser um indicador de mudanças no uso do espaço, tais como o uso mais intensivo dos territórios, associado a uma diminuição da área de forrageio (Walthall, 1999; Charles; Buikstra, 2002).

Um segundo tópico particularmente relevante é a subsistência dos primeiros americanos e suas implicações para a saúde bucal. $\bigcirc$ modelo clássico de subsistência dos primeiros americanos, assumindo que a cultura Clóvis seria a primeira sociedade a ocupar sistematicamente o território americano, propôs que o principal meio de subsistência inicial nas Américas seria a caça de grandes mamíferos, tais como o mamute e o mastodonte, por uma população humana formada por bandos pequenos e altamente móveis (Kelly; Todd, 1988), que teriam até mesmo gerado a extinção desses grandes animais (Martin, 1973). Após décadas de predominância deste modelo, tem ficado cada vez mais claro que essa subsistência foi uma interação particular entre os primeiros habitantes de algumas áreas temperadas da América do Norte com o meio ambiente. Na América do Sul, por exemplo, há poucas evidências de caça substancial de megamamíferos, sendo que, quando ela ocorre, é restrita ao extremo sul do continente (Borrero, 2009). A região de Lagoa Santa, em Minas Gerais, tem fornecido um estudo de caso extremamente relevante para essa temática, uma vez que a região combina um rico registro arqueológico com uma grande coleção de esqueletos humanos datados de até 10,5 mil anos atrás (Da-Gloria et al., 2017a, 2018). Caçadores-coletores usualmente apresentam baixa prevalência de cáries dentárias, uma vez que possuem uma dieta pobre em açúcares simples e rica em fibras e proteínas (Larsen, 2015). Em contraste, cáries dentárias são encontradas com frequência razoável na população de caçadores-coletores paleoamericanos de Lagoa Santa, especialmente entre as mulheres, com valores acima do que seria esperado para caçadores-coletores típicos das Américas (Da-Gloria; Larsen, 2014, 2017; Da-Gloria et al., 2017b). Por um lado, é comum em caçadores-coletores haver divisão de tarefas entre homens e mulheres, sendo que os homens tendem a comer alimentos mais ricos em proteína e as mulheres tendem a coletar plantas mais ricas em carboidrato (Marlowe, 2007). Por outro lado, baseando-se tanto em evidências arqueobotânicas e etnográficas como na prevalência de patologias dentais, é provável que os habitantes de Lagoa Santa tenham tido, de modo geral, uma dieta mais rica em plantas e tubérculos selvagens, que, combinados, apresentavam alto potencial cariogênico, afetando especialmente as mulheres (DaGloria; Larsen, 2014; Oliveira et al., 2018). Somado a isso, um estudo de isótopos de nitrogênio $\left(\delta^{15} \mathrm{~N}\right)$ feito em ossos humanos da coleção Lagoa Santa mostrou valores relativamente baixos, indicando uma posição desses indivíduos na cadeia trófica próxima de consumidores primários (Hermenegildo, 2009). Todavia, a amostra ainda é pequena, sendo ainda restrita a caracterização isotópica da ecologia local. De qualquer forma, considerando-se os desafios ecológicos de áreas tropicais, é bem provável que o uso e a manipulação de plantas nos primeiros habitantes da América do Sul tenham sido muito mais intensos do que em áreas temperadas das Américas.

Como dito anteriormente, a grande maioria de esqueletos humanos antigos nas Américas provém de achados isolados. Ainda assim, a inferência de subsistência pode ser feita através de análises de patologias orais e através da aplicação de métodos moleculares de isótopos estáveis em esqueletos individuais. A combinação de isótopos de carbono $\left(\delta^{13} \mathrm{C}\right)$ e de nitrogênio $\left(\delta^{15} \mathrm{~N}\right)$ pode diferenciar dietas terrestres de marinhas, alimentações

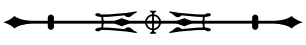


oriundas de biomas abertos ou sombreados e variações na posição trófica dos humanos no ecossistema (Katzenberg, 2008). Na América do Sul, Eggers et al. (2011) reportaram os valores de $\delta^{13} \mathrm{C}$ e $\delta^{15} \mathrm{~N}$ para um esqueleto de um adulto masculino jovem, exumado no sambaqui fluvial da Capelinha, em São Paulo, e datado em cerca de 10 mil anos atrás. Os autores inferiram uma dieta terrestre baseada em porcos do mato, veados e roedores. Além disso, eles relataram quatro cáries pequenas nesse esqueleto, o que pode indicar uso considerável dos recursos vegetais locais. Da mesma forma, Lessa e Guidon (2002) reportaram um esqueleto de adulto maduro datado indiretamente em cerca de 11,3 mil anos atrás, encontrado no abrigo da Toca dos Coqueiros, no Piauí. $\bigcirc$ esqueleto apresentou doença periodontal, lesão inflamatória, perda de dentes antemortem e uma possível cárie dentária, caracterizando sua saúde bucal como ruim. Além disso, o esqueleto de uma mulher adulta jovem, exumada no sítio Toca da Janela da Barra do Antonião, também no Piauí, e datado em cerca de 11 mil anos atrás, apresentou seis dentes com lesões de cáries (Peyre, 1993). Esses resultados, embora esparsos e preliminares, parecem corroborar a conclusão feita em Lagoa Santa de que os primeiros habitantes no Brasil apresentavam saúde bucal ruim e uso mais intenso de recursos vegetais ricos em amido, tais como frutas e tubérculos.

Os esqueletos datados em estratos antigos na América do Norte, como já dito anteriormente, são também bastante esparsos. Análises de evidências isotópicas de remanescentes humanos encontrados na caverna On Your Knees, no sudeste do Alasca, datados em cerca de 10,3 mil anos atrás, apresentaram valores de $\delta^{13} \mathrm{C}$ condizentes com uma dieta baseada em alimentos marinhos (Dixon et al., 1997). Já a evidência de $\delta^{13} \mathrm{C}$ e $\delta^{15} \mathrm{~N}$ obtida do esqueleto de Buhl, encontrado em Idaho e datado em 12,6 mil anos atrás, sugeriu dieta baseada principalmente em salmão, mas também incluindo carne de fontes terrestres (Green et al., 1998). A análise isotópica do esqueleto de Kennewick, encontrado em Washington e datado em 8,5 mil anos atrás, mostrou dieta baseada fortemente em peixes e possivelmente em aves (Schwarcz et al., 2014). $O$ esqueleto de uma mulher adulta encontrado em Arch Lake, no Novo México, e datado em 11,5 mil anos atrás forneceu valores isotópicos consistentes com dieta rica em proteínas (Owsley et al., 2010). Esses dados isotópicos mostram diversidade de fontes alimentares, como seria esperado em caçadores-coletores, muito embora haja clara ênfase no consumo de proteína animal. Os dados de saúde bucal desses forrageadores antigos da América do Norte parecem corroborar essas afirmações. Powell e Steele (1994) realizaram um estudo dos dentes de dez esqueletos encontrados em uma área de Minnesota até o Texas e datados entre 11,5 a 8,5 mil anos atrás. Os resultados mostraram baixa prevalência de cáries ( $0,4 \%$ dos dentes), sugerindo dieta relativamente pobre em plantas. Achados posteriores, tais como a mulher de Buhl (idade de cerca de 20 anos) e o homem de Kennewick (idade entre 35 a 39 anos), não apresentaram cáries dentárias nos seus dentes, com 25 e 30 dentes analisados respectivamente (Green et al., 1998; Owsley et al., 2014).

Em síntese, o panorama do estilo de vida dos primeiros habitantes do continente mostra diversidade de rituais mortuários, com presença de manipulação do corpo e acompanhamentos funerários. Ao mesmo tempo, o padrão de subsistência dessas populações é muito mais diversificado do que se imaginava há algumas décadas, incluindo estratégia tropical de uso intensivo de plantas e estratégia mais voltada ao consumo de carne animal em regiões temperadas e frias. É notável que há cerca de 12 mil anos, quando os esqueletos humanos começam a aparecer no registro arqueológico nas Américas, encontrava-se alta diversidade adaptativa e cultural baseada nas indústrias líticas locais (Araujo et al., 2015). Nesse aspecto, é preciso avaliar a possibilidade de que a ocupação das Américas foi mais antiga do que se é estabelecido pelos dados genéticos ou, alternativamente, que as populações humanas apresentaram flexibilidade adaptativa muito grande frente aos desafios ecológicos encontrados no continente.

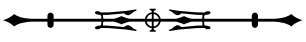




\section{DISCUSSÃO E CONCLUSÕES}

As evidências bioarqueológicas sobre a ocupação inicial das Américas mostram que há diversos níveis de consenso em relação aos modelos de ocupação. A rota inicial de entrada é o tema com maior consenso entre os pesquisadores, apontando para a Beríngia como a única via de chegada de populações asiáticas nas Américas. Ainda assim, há grupos minoritários que defendem entradas adicionais via Europa, África e Polinésia, porém sem evidências empíricas fortes. A data inicial de entrada nas Américas tem mostrado um consenso intermediário. O pensamento majoritário tem tido forte influência dos estudos genéticos atuais, que incluem métodos de coalescência oriundos do sequenciamento em larga escala de DNA autossômico e uniparental, obtido de populações atuais e antigas. $\bigcirc$ modelo genético mais influente é chamado de MPB, e propõe que a expansão ao sul da Beríngia ocorreu há 16 mil anos atrás, após período de permanência e de isolamento na Beríngia. A ausência de esqueletos humanos mais antigos do que 14 mil anos corrobora esse modelo. Por outro lado, há um grupo considerável de arqueólogos, com destaque para pesquisadores da América do Sul, que acreditam haver evidências de ocupações anteriores a 16 mil anos nas Américas (Boëda et al., 2014; Dillehay et al., 2015; Vialou et al., 2017). Já o número de migrações para as Américas é a questão com menor consenso entre pesquisadores. O MFGR é o modelo preferido entre os geneticistas, que acreditam ter havido uma migração única principal e depois migrações posteriores restritas ao ártico. Já entre os morfologistas, alguns acreditam no MDCBP, que propõe a entrada de duas levas biológicas principais para as Américas (Neves; Hubbe, 2005), enquanto outros buscam compatibilizar a variação craniométrica no continente com o modelo genético, propondo uma entrada única composta por uma população altamente variável (González-José et al., 2008; De Azevedo et al., 2011, 2017) ou por uma população que tenha se modificado in situ por fatores ambientais (Perez; Monteiro, 2009; Perez et al., 2011; Menéndez et al., 2014) ou estocásticos (Galland; Friess, 2016). Por fim, pesquisas sobre o modo de vida das primeiras populações americanas ainda têm sofrido com a escassez de dados e a complexidade das interações entre humanos e ambiente. Os estudos que se utilizam de dados biológicos para investigar essa questão têm mostrado que os primeiros americanos apresentavam tanto rituais mortuários como subsistência bastante variáveis. Essa variabilidade já era presente há 12 mil anos, aventando a possibilidade de que essas populações ou apresentavam alta flexibilidade adaptativa ou mesmo já estavam estabelecidas nas Américas há mais tempo do que é usualmente aceito.

Por fim, é importante delinear brevemente as lacunas de pesquisa e as perspectivas de investigação sobre o tema, especialmente em contexto brasileiro. No campo da genética, ainda há poucos casos de extração de DNA antigo a partir de esqueletos brasileiros. De fato, há exemplos de extração de DNA mitocondrial em sambaquis do Rio de Janeiro (Marinho et al., 2006), em concheiros da Amazônia (Ribeiro-dos-Santos et al., 2010), em botocudos do Brasil central (Gonçalves et al., 2013) ${ }^{8}$ e, recentemente, de DNA autossômico dos paleoamericanos de Lagoa Santa e dos sambaquieiros de São Paulo e de Santa Catarina (Moreno-Mayar et al., 2018b; Posth et al., 2018). A obtenção de DNA antigo em contexto brasileiro pode ter uma contribuição relevante para o entendimento da demografia e de movimentos populacionais nas Américas. Já no campo morfológico, há uma grande demanda pela escavação de novas coleções esqueletais que preencham certas lacunas temporais e espaciais no Brasil. Há pouquíssimos esqueletos humanos mais antigos do que 10 mil anos no Brasil, assim como não há grandes coleções esqueletais datadas do Holoceno Médio no interior do Brasil. Esses períodos são essenciais para o teste da continuidade morfológica entre as populações humanas

\footnotetext{
8 Ver Malaspinas et al. (2014), para extração de DNA autossômico.
}

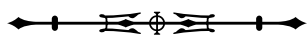


antigas e atuais. Outro aspecto significativo é a ausência de grandes coleções esqueletais em muitos estados brasileiros, especialmente no Norte e no Centro-Oeste, impedindo que se tenha um panorama da diversidade morfológica e cultural no território brasileiro. Essa ausência de coleções esqueletais, que usualmente é atribuída às condições tropicais úmidas do Brasil, pode ser melhor explicada pela ausência de investimento humano e financeiro em projetos de escavação de sítios com remanescentes biológicos humanos (Mendonça de Souza, 2010).

Por fim, os estudos sobre saúde e estilo de vida são uma área com potencial de crescimento no contexto dos primeiros americanos, pois têm a capacidade de revelar conexões entre humanos e ambiente ainda não exploradas. O crescimento e a expansão desses estudos estão ligados diretamente ao desenvolvimento de novas técnicas de análise óssea, tais como a análise de isótopos estáveis, que permite a obtenção de informações sobre subsistência em materiais bastante fragmentados. Porém, acima de tudo, é preciso investir no aumento de coleções esqueletais antigas, na adequação das reservas técnicas (com controle de temperatura e umidade) para o recebimento desses materiais orgânicos e no treinamento de uma massa crítica de pesquisadores na área de bioarqueologia no Brasil.

\section{REFERÊNCIAS}

ACHILLI, Alessandro; PEREGO, Ugo A.; BRAVI, Claudio M.; COBLE, Michael D.; KONG, Qing-Peng; WOODWARD, Scott R.; SALAS, Antonio; TORRONI, Antonio; BANDELT, Hans-jürgen. The phylogeny of the four Pan-American mtDNA haplogroups: implications for evolutionary and disease studies. PloS One, San Francisco, v. 3, n. 3, p. e1764, Mar. 2008. DOI: https://doi. org/10.1371/journal.pone.0001764.

AMORIM, Carlos Eduardo G.; NUNES, Kelly; MEYER, Diogo; COMAS, David; BORTOLINI, Maria Cátira; SALZANO, Francisco Mauro; HÜNEMEIER, Tábita. Genetic signature of natural selection in first Americans. PNAS, Washington, v. 114, n. 9, p. 2195-2199, Feb. 2017. DOI: https://doi.org/10.1073/pnas.1620541114.

ARAUJO, Astolfo G. M. On vastness and variability: cultural transmission, historicity, and the Paleoindian record in Eastern South America. Anais da Academia Brasileira de Ciências, Rio de Janeiro, v. 87, n. 2, p. 1239-1258, abr./jun. 2015. DOI: http://dx.doi. org/10.1590/0001-3765201520140219.
BECERRA-VALDIVIA, Lorena; WATERS, Michael R.; STAFFORD JÚNIOR, Thomas W.; ANZICK, Sarah L.; COMESKEY, Daniel; DEVIĖSE, Thibaut; HIGHAM, Thomas. Reassessing the chronology of the archaeological site of Anzick. PNAS, Washington, v. 115, n. 27, p. 7000-7003, July 2018. DOI: https://doi.org/10.1073/pnas.1803624115.

BERNARDO, Danilo Vicensotto. Afinidades morfológicas intra e extra-continentais dos paleoíndios de Lagoa Santa: uma nova abordagem. 2007. Dissertação (Mestrado em Ciências) - Instituto de Biociências, Universidade de São Paulo, São Paulo, 2007.

BLACK, F. L.; PANDEY, J. P.; SANTOS, S. E. B. Evidências baseadas em HLA e IgG sobre as relações intra e intercontinentais das populações nativas da Amazônia. In: NEVES, Walter A. (org.). Origens, adaptações e diversidade biológica do homem nativo da Amazônia. Belém: MPEG, 1991. p. 55-83.

BODNER, Martin; PEREGO, Ugo A.; HUBER, Gabriela; FENDT, Liane; RÖCK, Alexander W.; ZIMMERMANN, Bettina; OLIVIERI, Anna; GÓMEZ-CARBALLA, Alberto; LANCIONI, Hovirag; ANGERHOFER, Norman; BOBILLO, Maria Cecilia; CORACH, Daniel; WOODWARD, Scott R.; SALAS, Antonio; ACHILLI, Alessandro; TORRONI, Antonio; BANDELT, Hans-Jürge; PARSON, Walther. Rapid coastal spread of First Americans: novel insights from South America's Southern Cone mitochondrial genomes. Genome Research, Cold Spring Harbor, v. 22, p. 811-820, Feb. 2012. DOI: http://www.genome.org/cgi/doi/10.1101/gr.131722.111.

BOËDA, Eric; CLEMENTE-CONTE, Ignacio; FONTUGNE, Michel; LAHAYE, Christelle; PINO, Mario; FELICE, Gisele Daltrini; GUIDO, Niède; HOELTZ, Sirlei; LOURDEAU, Antoine; PAGLI, Marina; PESSIS, Anne-Marie; VIANA, Sibeli; DA COSTA, Amélia; DOUVILLE, Eric. A new late Pleistocene archaeological sequence in South America: the Vale da Pedra Furada (Piaui, Brazil). Antiquity, Cambridge, v. 88, n. 341, p. 927-955, Sept. 2014. DOI: https://doi. org/10.1017/S0003598X00050845.

BONATTO, Sandro L.; SALZANO, Francisco M. Diversity and age of the four major mtDNA haplogroups, and their implications for the peopling of the New World. American Journal of Human Genetics, Amsterdam, v. 61, n. 6, p. 1413-1423, Dec. 1997. DOI: https://doi.org/10.1086/301629.

BORRERO, Luis Alberto. The elusive evidence: the archeological record of the South American extinct megafauna. In: Haynes, Gary (org.). American megafaunal extinctions at the end of the pleistocene. New York: Springer, 2009. p. 145-168.

BOURGEON, Lauriane; BURKE, Ariane; HIGHAM, Thomas. Earliest human presence in North America dated to the Last Glacial Maximum: new radiocarbon dates from Bluefish Caves, Canada. PLoS One, San Francisco, v. 12, n. 1, p. e0169486, Jan. 2017. DOI: https://doi.org/10.1371/journal.pone.0169486.

BRADLEY, Bruce; STANFORD, Dennis. The North Atlantic ice-edge corridor: a possible Palaeolithic route to the new world. World Archaeology, London, v. 36, n. 4, p. 459-478, Nov. 2004. DOI: https://doi.org/10.1080/0043824042000303656.

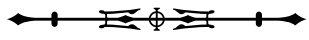


BRAJE, Todd I.; DILLEHAY, Tom D.; ERLANDSON, Jon M.; FITZPATRICK, Scott M.; GRAYSON, Donald K.; HOLLIDAY, Vance T.; KELLY, Robert L.; KLEIN, Richard G.; MELTZER, David J.; RICK, Torben C. Were hominins in California $\sim 130,000$ years ago? PaleoAmerica, Abingdon-on-Thames, v. 3, n. 3, p. 200-202, July 2017. DOI: https://doi.org/10.1080/20555563.2017.1348091.

BUENO, Lucas; DIAS, Adriana Schmidt; STEELE, James. The late Pleistocene/Early Holocene archaeological record in Brazil: a geo-referenced database. Quaternary International, Amsterdam, v. 301, p. 74-93, July 2013. DOI: https://doi.org/10.1016/j. quaint.2013.03.042.

CHARLES, Douglas K.; BUIKSTRA, Jane E. Siting, sighting, and citing the dead. Archaeological Papers of the American Anthropological Association, Hoboken, v. 11, n. 1, p. 13-25, Jan. 2002. DOI: https:// doi.org/10.1525/ap3a.2002.11.1.13.

CHATTERS, James C.; KENNETT, Douglas J; ASMEROM, Yemane; KEMP, Brian M.; POLYAK, Victor; BLANK, Alberto Nava; BEDDOWS, Patricia A.; REINHARDT, Eduard; ARROYO CABRALES, Joaquin; BOLNICK, Deborah A.; MALHI, Ripan S.; CULLETON, Brendan J.; ERREGUERENA, Pilar Luna; RISSOLO, Dominique; MORELLHART, Shanti; STAFFORD JÚNIOR, Thomas W. Late Pleistocene human skeleton and mtDNA link Paleoamericans and modern Native Americans. Science, Washington, v. 344, n. 6185, p. 750-754, May 2014. DOI: https://doi.org/10.1126/science.1252619.

CLARKSON, Chris; JACOBS, Zenobia; MARWICK, Ben; FULLAGAR, Richard; WALLIS, Lynley; SMITH, Mike; ROBERTS, Richard G.; HAYES, Elspeth; LOWE, Kelsey; CARAH, Xavier; FLORIN, S. Anna; MCNEIL, Jessica; COX, Delyth; ARNOLD, Lee J.; HUA, Quan; HUNTLEY, Jillian; BRAND, Helen E. A.; MANNE, Tiina; FAIRBAIRN, Andrew; SHULMEISTER, James; LYLE, Lindsey; SALINAS, Makiah; PAGE, Mara; CONNELL, Kate; PARK, Gayoung; NORMAN, Kasih; MURPHY, Tessa; PARDOE, Colin. Human occupation of northern Australia by 65,000 years ago. Nature, London, v. 547, p. 306-310, July 2017.

COLLINS, M. J.; NIELSEN-MARSH, C. M.; HILLER, J.; SMITH, C. I.; ROBERTS, J. P.; PRIGODICH, R. V.; WESS, T. J.; CSAPÓ, J.; MILLARD, A. R.; TURNER-WALKER, G. The survival of organic matter in bone: a review. Archaeometry, Oxford, v. 44, n. 3, p. 383-394, Aug. 2002. DOI: https://doi.org/10.1111/1475-4754.t01-1-00071.

CORREAL URREGO, Gonzalo. Investigaciones arqueológicas en abrigos rocosos de Nemocon y Sueva. Bogotá: Fundación de Investigaciones Arqueológica Nacionales: Banco de la República, 1979.

CRAMON-TAUBADEL, Noreen von. Global human mandibular variation reflects differences in agricultural and hunter-gatherer subsistence strategies. PNAS, Washington, v. 108, n. 49, p. 19546 19551, Dec. 2011. DOI: https://doi.org/10.1073/pnas.1113050108.

CRAMON-TAUBADEL, Noreen von; STRAUSS, André; HÜBBE, Mark. Evolutionary population history of early Paleoamerican cranial morphology. Science Advances, Washington, v. 3, n. 2, p. e1602289, Feb. 2017. DOI: https://doi.org/10.1126/sciadv.1602289.
CRAWFORD, Michael $H$. The origins of Native Americans: evidence from anthropological genetics. Cambridge: Cambridge University Press, 1998.

DA-GLORIA, Pedro; HUBBE, Mark; NEVES, Walter Alves. Lagoa Santa's contribution to the origins and life of early Americans. Evolutionary Anthropology, Hoboken, v. 27, n. 3, p. 121-133, May/June 2018. DOI: https://doi.org/10.1002/evan.21587.

DA-GLORIA, Pedro; LARSEN, Clark Spencer. Subsisting at the Pleistocene/Holocene boundary in the New World: a view from the Paleoamerican mouths of Central Brazil. Paleoamerica, London, v. 3, n. 2, p. 101-121, Jan. 2017. DOI: https://doi.org/10. 1080/20555563.2016.1270697.

DA-GLORIA, Pedro; NEVES, Walter Alves; HÜBBE, Mark (ed.). Archaeological and paleontological research in Lagoa Santa: the quest for the first Americans. Cham, Switzerland: Springer, 2017a.

DA-GLORIA, Pedro; OLIVEIRA, Rodrigo E.; NEVES, Walter Alves. Dental caries at Lapa do Santo, central-eastern Brazil: an Early Holocene archaeological site. Anais da Academia Brasileira de Ciências, Rio de Janeiro, v. 89, n. 1, p. 307-316, jan./mar. 2017b. DOI: http://dx.doi.org/10.1590/0001-3765201620160297.

DA-GLORIA, Pedro; LARSEN, Clark Spencer. Oral health of the Paleoamericans of Lagoa Santa, Central Brazil. American Journal of Physical Anthropology, Hoboken, v. 154, n. 1, p. 11-26, May 2014. DOI: https://doi.org/10.1002/ajpa.22467.

DE AZEVEDO, Soledad; QUINTO-SÁNCHEZ, Mirsha; PASCHETTA, Carolina; GONZÁLEZ-JOSÉ, Rolando. The first human settlement of the New World: a closer look at craniofacial variation and evolution of early and late Holocene Native American groups. Quaternary International, Amsterdam, v. 431, Part B, p. 152-167, Feb. 2017. DOI: https://doi.org/10.1016/j. quaint.2015.11.012.

DE AZEVEDO, Soledad; BORTOLINI, María C.; BONATTO, Sandro Luis; HÜNEMEIER, Tábita; SANTOS, Fabricio; GONZÁLEZ-JOSÉ, Rolando. Ancient remains and the first peopling of the Americas: reassessing the Hoyo Negro skull. American Journal of Physical Anthropology, Hoboken, v. 158, n. 3, p. 514 521, Nov. 2015. DOI: http://doi.org/10.1002/ajpa.22801.

DE AZEVEDO, Soledad; NOCERA, Ariadna; PASCHETTA, Carolina; CASTILLO, Lucía; GONZÁLEZ, Marina; GONZÁLEZJOSÉ, Rolando. Evaluating microevolutionary models for the early settlement of the New World: the importance of recurrent gene flow with Asia. American Journal of Physical Anthropology, Hoboken, v. 146, n. 4, p. 116-129, Dec. 2011. DOI: https://doi.org/10.1002/ ajpa. 21564

DELGADO, Miguel Eduardo. Holocene population history of the Sabana de Bogotá region, Northern South America: an assessment of the craniofacial shape variation. American Journal of Physical Anthropology, Hoboken, v. 162, n. 2, p. 350-369, Feb. 2017. DOI: https://doi.org/10.1002/ajpa.23124.

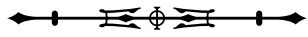


DEVOR, Eric J. Transmission of human craniofacial dimensions. Journal of Craniofacial Genetics and Developmental Biology, Bethesda, v. 7, n. 2, p. 95-106, Feb. 1987.

DILLEHAY, Tom D.; OCAMPO, Carlos; SAAVEDRA, José; SAWAKUCHI, Andre Oliveira; VEGA, Rodrigo M.; PINO, Mario; COLLINS, Michael B.; CUMMINGS, Linda Scott; ARREGUI, Iván; VILLAGRAN, Ximena S.; HARTMANN, Gelvam A.; MELLA, Mauricio; GONZÁLEZ, Andrea; DIX, George. New archaeological evidence for an early human presence at Monte Verde, Chile. PLoS One, São Francisco, v. 10, n. 11, p. e0141923, Nov. 2015. DOI: https://doi.org/10.1371/journal.pone.0141923.

DILLEHAY, Tom D. Probing deeper into first American studies. PNAS, Washington, v. 106, n. 4, p. 971-978, Jan. 2009. DOI: https://doi.org/10.1073/pnas.0808424106.

DILLEHAY, Tom D. The settlement of the Americas: a new prehistory. New York: Basic Books, 2000.

DIXON, E. James. Late Pleistocene colonization of North America from Northeast Asia: new insights from large-scale paleogeographic reconstructions. Quaternary International, Amsterdam, v. 285, p. 57-67, Feb. 2013. DOI: https://doi.org/10.1016/j. quaint.2011.02.027.

DIXON, E. James; HEATON, Timothy H.; FIFIELD, Terence E.; HAMILTON, Thomas D.; PUTNAM, David E.; GRADY, Frederick. Late Quaternary regional geoarchaeology of Southeast Alaska Karst: a progress report. Geoarchaeology, Hoboken, v. 12, n. 6 , p. 689-712, Sept. 1997. DOI: https://doi.org/10.1002/(SICI)15206548(199709)12:6<689::AID-GEA8>3.0.CO;2-V.

EGGERS, Sabine; PARKS, Maria; GRUPE, Gisela; REINHARD, Karl J. Paleoamerican diet, migration and morphology in Brazil: Archaeological complexity of the earliest Americans. PLoS One, São Francisco, v. 6, n. 9, p. e23962, Sept. 2011. DOI: https://doi. org/10.1371/journal.pone.0023962.

ELIAS, Scott A. Setting the stage: environmental conditions in Beringia as people entered the New World. In: JABLONSKI, Nina G. (ed.). The first Americans: the Pleistocene colonization of the New World. San Francisco: California Academy of Sciences, 2002. p. 9-25.

ERLANDSON, Jon M.; BRAJE, Todd J.; GILL, Kristina M.; GRAHAM, Michael $H$. Ecology of the kelp highway: did marine resources facilitate human dispersal from Northeast Asia to the Americas? The Journal of Island and Coastal Archaeology, London, v. 10, n. 3, p. 392-411, Feb. 2015. DOI: https://doi.org/ 10.1080/15564894.2014.1001923.

ERLANDSON, Jon M.; GRAHAM, Michael H.; BOURQUE, Bruce J.; CORBETT, Debra; ESTES, James A.; STENECK, Robert S. The kelp highway hypothesis: marine ecology, the coastal Migration Theory, and the peopling of the Americas. The Journal of Island and Coastal Archaeology, London, v. 2, n. 2, p. 161-174, Oct. 2007. DOI: https://doi.org/10.1080/15564890701628612.
FAGAN, Brian M. The journey from Eden: the peopling of our world. London: Thames and Hudson, 1990.

FAGUNDES, Nelson J. R.; KANITZ, Ricardo; BONATTO, Sandro $\mathrm{L}$. A reevaluation of the Native American MtDNA genome diversity and its bearing on the models of early colonization of Beringia. PloS One, São Francisco, v. 3, n. 9, p. e3157, Sept. 2008. DOI: https:// doi.org/10.1371/journal.pone.0003157.

FEHREN-SCHMITZ, Lars; LLAMAS, Bastien; LINDAUER, Susanne; TOMASTO-CAGIGAO, Elsa; KUZMINSKY, Susan; ROHLAND, Nadin; SANTOS, Fabricio R.; KAULICKE, Peter; VALVERDE, Guido; RICHARDS, Stephen M.; NORDENFELT, Susanne; SEIDENBERG, Verena; MALLICK, Swapan; COOPER, Alan; REICH, David; HAACK, Wolfgang. A re-appraisal of the early Andean human remains from Lauricocha in Peru. PLoS One, São Francisco, v. 10, n. 6, p. e0127141, June 2015. DOI: https://doi.org/10.1371/journal.pone.0127141.

FIEDEL, Stuart J. The peopling of the New World: present evidence, new theories, and future directions. Journal of Archaeological Research, Berlin, v. 8, n. 1, p. 39-103, Mar. 2000.

GALLAND, Manon; FRIESS, Martin. A three-dimensional geometric morphometrics view of the cranial shape variation and population history in the New World. American Journal of Human Biology, Hoboken, v. 28, n. 5, p. 646-661, Sept. 2016. DOI: https://doi. org/10.1002/ajhb.22845.

GONÇALVES, Vanessa Farias; STENDERUP, Jesper; RODRIGUESCARVALHO, Cláudia; SILVA, Hilton P.; GONÇALVES-DORNELAS, Higgor; LÍRYO, Andersen; KIVISILD, Toomas; MALASPINAS, AnnaSapfo; CAMPOS, Paula F; RASMUSSEN, Morten; WILLERSLEV, Eske; PENA, Sergio Danilo J. Identification of Polynesian mtDNA haplogroups in remains of Botocudo Amerindians from Brazil. PNAS, Washington, v. 110, n. 16, p. 6465-6469, Apr. 2013. DOI: https://doi. org/10.1073/pnas.1217905110.

GONÇALVES, Vanessa Farias; PARRA, Flavia C.; GONÇALVESDORNELAS, Higgor; RODRIGUES-CARVALHO, Claudia; SILVA, Hilton P.; PENA, Sergio D. J. Recovering mitochondrial DNA lineages of extinct Amerindian nations in extant homopatric Brazilian populations. Investigative Genetics, London, v. 1, n. 1, p. 1-13, Dec. 2010. DOI: https://doi.org/10.1186/2041-2223-1-13.

GONZÁLEZ-JOSÉ, Rolando; BORTOLINI, Maria Cátira; SANTOS, Fabricio R.; BONATTO, Sandro L. The peopling of America: craniofacial shape variation on a continental scale and its interpretation from an interdisciplinary view. American Journal of Physical Anthropology, Hoboken, v. 137, n. 2, p. 175-187, Oct. 2008. DOI: https://doi.org/10.1002/ajpa.20854.

GONZÁLEZ-JOSÉ, Rolando; NEVES, Walter; LAHR, Marta Mirazón; GONZÁLEZ, Silvia; PUCCIARELLI, Héctor; MARTíNEZ, Miquel Hernández; CORREAL, Gonzalo. Late Pleistocene/Holocene craniofacial morphology in Mesoamerican Paleoindians: implications for the peopling of the New World. American Journal of Physical Anthropology, Hoboken, v. 128, n. 4, p. 772-780, Dec. 2005. DOI: https://doi.org/10.1002/ajpa.20165.

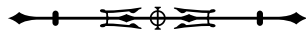


GONZÁLEZ-JOSÉ, Rolando; MOLEN, Silvina van der; GONZÁLEZ-PÉREZ, Emili; HERNÁNDEZ, Miquel. Patterns of phenotypic covariation and correlation in modern humans as viewed from morphological integration. American Journal of Physical Anthropology, Hoboken, v. 123, n. 1, p. 69-77, Jan. 2004. DOI: https://doi.org/10.1002/ajpa.10302.

GONZÁLEZ-JOSÉ, Rolando; GONZÁLEZ-MARTÍN, Antonio; HERNÁNDEZ, Miquel; PUCCIARELLI, Héctor M.; SARDI, Marina; ROSALES, Alfonso; MOLEN, Silvina van der. Craniometric evidence for Palaeoamerican survival in Baja California. Nature, London, v. 425, n. 6953, p. 62-65, Sept. 2003.

GREEN, Thomas J.; COCHRAN, Bruce; FENTON, Todd W.; WOODS, James C.; TITMUS, Gene L.; TIESZEN, Larry; DAVIS, Mary Anne; MILLER, Susanne J. The Buhl burial: a paleoindian woman from Southern Idaho. American Antiquity, Cambridge, v. 63, n. 3, p. 437-456, July 1998. DOI: https://doi.org/10.2307/2694629.

GREENBERG, Joseph H.; TURNER II, Christy G.; ZEGURA, Stephen L. The settlement of the Americas: a comparison of the linguistic, dental and genetic evidence. Current Anthropology, Chicago, v. 27, n. 5, p. 477-497, Dec. 1986. DOI: https://doi. org/10.1086/203472.

GUIDON, Niède. Pré-história da região do Parque Nacional Serra da Capivara. Ciência \& Ambiente, Santa Maria, v. 48, p. 217-230, jan./jul. 2014.

GUIDON, Niéde; PEYRE, Evelyne; GUÉRIN, Claude; COPPENS, Yves. Resultados da datação de dentes humanos da Toca do Garrincho, Piauí, Brasil. Clio-Série Arqueológica, Recife, n. 14, p. 75-86, 2000

HARRIS, Eugene E. Ancestors in our genome: the new science of human evolution. Oxford: Oxford University Press, 2015.

HARVATI, Katerina; WEAVER, Timothy D. Human cranial anatomy and the differential preservation of population history and climate signatures. The Anatomical Record, Hoboken, v. 288A, n. 12, p. 1225-1233, Dec. 2006. DOI: https://doi.org/10.1002/ar.a.20395.

HEDGES, Robert E. M. Bone diagenesis: an overview of processes. Archaeometry, Oxford, v. 44, n. 3, p. 319-328, Aug. 2002. DOI: https://doi.org/10.1111/1475-4754.00064.

HERMENEGILDO, Tiago. Reconstituição da dieta e dos padrões de subsistência das populações pré-históricas de caçadorescoletores do Brasil Central através da ecologia isotópica. 2009. Dissertação (Mestrado em Ecologia Aplicada) - Escola Superior de Agricultura "Luiz de Queiroz", Universidade de São Paulo, Piracicaba, 2009.

HEYERDAHL, Thor. A expedição Kon-tiki. Rio de Janeiro: José Olympio, 2013.

HOFFECKER, John F.; ELIAS, Scott A.; O'ROURKE, Dennis H. Out of Beringia? Science, Washington, v. 343, n. 6174, p. 979-980, Feb. 2014. DOI: https://doi.org/10.1126/science.1250768.
HOLEN, Steven R.; DEMÉRÉ, Thomas A.; FISHER, Daniel C.; FULLAGAR, Richard; PACES, James B.; JEFFERSON, George T.; BEETON, Jared M.; CERUTTI, Richard A.; ROUNTREY, Adam N.; VESCERA, Lawrence; HOLEN, Kathleen A. A 130,000-year-old archaeological site in southern California, USA. Nature, London, v. 544, n. 7651, p. 479-483, Apr. 2017. DOI: https://doi.org/10.1038/nature22065.

HRDLIČKA, Ales. Early man in America: what have the bones to say? In: MACCURDY, George Grant (ed.). Early man as depicted by the leading authorities at the International Symposium at the Academy of Natural Sciences, Philadelphia, March 1937. Philadelphia: J. B. Lippincott Company, 1937. p. 93-104.

HRDLIČKA, Ales. The coming of man from Asia in light of recent discoveries. Proceedings of the American Philosophical Society, Philadelphia, v. 71, n. 6, p. 393-402, Apr. 1932.

HRDLIČKA, Ales. The peopling of Asia. Proceedings of the American Philosophical Society, Philadelphia, v. 60, n. 4, p. 535545, 1921.

HRDLIČKA, Ales. Early man in South America. Washington: Government Printing Office, 1912. (Bureau of American Ethnology, Bulletin 52).

HU, Aixue; MEEHL, Gerald A.; OTTO-BLIESNER, Bette L.; WAELBROECK, Claire; HAN, Weiqing; LOUTRE, Marie-France; LAMBECK, Kurt; MITROVICA, Jerry X.; ROSENBLOOM, Nan. Influence of Bering Strait flow and North Atlantic circulation on glacial sea-level changes. Nature Geosciences, London, v. 3, p. 118-121, Feb. 2010. DOI: https://doi.org/10.1038/ngeo729.

HUBBE, Mark; NEVES, Walter Alves. The repercussions of the human skeletons from Lagoa Santa in the international scenario. In: DA-GLORIA, Pedro; NEVES, Walter Alves; HUBBE, Mark (ed.). Archaeological and paleontological research in Lagoa Santa: the quest for the first Americans. Cham, Switzerland: Springer, 2017. p. 215-231.

HUBBE, Mark; STRAUSS, André; HÜBBE, Alex; NEVES, Walter Alves. Early South Americans cranial morphological variation and the origin of American biological diversity. PLoS One, São Francisco, v. 10, n. 10, p. e0138090, Oct. 2015. DOI: https://doi.org/10.1371/ journal.pone.0138090.

HUBBE, Mark; OKUMURA, Mercedes; BERNARDO, Danilo Vicensotto; NEVES, Walter Alves. Cranial morphological diversity of Early, Middle and Late Holocene Brazilian groups: implications for human dispersion in Brazil. American Journal of Physical Anthropology, Hoboken, v. 155, n. 4, p. 546-558, Dec. 2014. DOI: https://doi.org/10.1002/ajpa.22607.

HUBBE, Mark; HARVATI, Katerina; NEVES, Walter Alves. Paleoamerican morphology in the context of European and East Asian late Pleistocene variation: implications for human dispersion into the New World. American Journal of Physical Anthropology, Hoboken, v. 144, n. 3, p. 442-453, Mar. 2011. DOI: https://doi. org/10.1002/ajpa.21425.

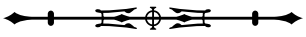


HUBBE, Mark; NEVES, Walter Alves; HARVATI, Katerina. Testing evolutionary and dispersion scenarios for the settlement of the New World. PLoS One, São Francisco, v. 5, n. 6, p. e11105, June 2010. DOI: https://doi.org/10.1371/journal.pone.0011105.

HUBBE, Mark; HANIHARA, Tsunehiko; HARVATI, Katerina. Climate signatures in the morphological differentiation of worldwide modern human populations. The Anatomical Record, Hoboken, v. 292, n. 11, p. 1720-1733, Nov. 2009. DOI: https://doi.org/10.1002/ar.20976.

HUBBE, Mark; NEVES, Walter Alves; AMARAL, Heleno Licurgo do; GUIDON, Niède. "Zuzu" strikes again - morphological affinities of the Early Holocene human skeleton from Toca dos Coqueiros, Piaui, Brazil. American Journal of Physical Anthropology, Hoboken, v. 134, n. 2, p. 285-291, Oct. 2007. DOI: https://doi.org/10.1002/ajpa.20668.

HUBBE, Mark; NEVES, Walter Alves; ATUÍ, João Paulo Vezzani; CARTELLE, Cástor; SILVA, Miya A. Pereira da. A new early human skeleton from Brazil: support for the "two main biological components model" for the settlement of the Americas. Current Research in the Pleistocene, College Station, v. 21, p. 77-81, 2004.

HUFFMAN, Michaela Marie. Biological variation in South American populations using dental non-metric traits: assessment of isolation by time and distance. 2014. Tese (Doutorado em Antropologia) - Ohio State University, Columbus, 2014

JANTZ, Richard L.; OWSLEY, Douglas W. Variation among early North America crania. American Journal of Physical Anthropology, Hoboken, v. 114, n. 2, p. 146-155, Feb. 2001. DOI: https://doi.org/10.1002/1096-8644(200102)114:2<146::AIDAJPA1014>3.0.CO;2-E.

JODRY, Margaret A.; OWSLEY, Douglas W. A new look at the double burial from Horn Shelter No. 2. In: OWSLEY, Douglas W.; JANTZ, Richard L. (ed.). Kennewick man: the scientific investigation of an ancient american skeleton. College Station: Texas A\&M University Press, 2014. p. 549-604.

KATZENBERG, M. Anne. Stable isotope analysis: a tool for studying past diet, demography, and life history. In: KATZENBERG, M. Anne; SAUNDERS, Shelley R. (ed.). Biological anthropology of the human skeleton. 2nd ed. New York: Wiley Liss, Inc., 2008. p. 413-441.

KELLY, Robert L.; TODD, Lawrence C. Coming into the country: early Paleoindian hunting and mobility. American Antiquity, Cambridge, v. 53, n. 2, p. 231-244, Apr. 1988. DOI: https://doi.org/10.2307/281017.

$\mathrm{KIRCH}$, Patrick Vinton. On the road of the winds: an archaeological history of the Pacific Islands before European contact. 2nd ed. Oakland: University of California Press, 2017.

KUZMINSKY, Susanna C.; BÁEZ, Omar Reyes; ARRIAZA, Bernanrdo; MÉNDEZ, César; STANDEN, Vivien G.; SAN ROMÁN, Manuel; MUÑOZ, Iván; DURÁN HERRERA, Ángel; HUBBE, Mark. Investigating cranial morphological variation of early human skeletal remains from Chile: a 3D geometric morphometric approach. American Journal of Physical Anthropology, Hoboken, v. 165, n. 2, p. 223-237, 2018.
KUZMINSKY, Susanna C.; COONERTY, Nina; FEHREN-SCHMITZ, Lars. A reassessment of human cranial indices through the Holocene and their implications for the peopling of South America. Journal of Archaeological Science: Reports, Amsterdam, v. 11, p. 709-716, Feb. 2017. DOI: https://doi.org/10.1016/j.jasrep.2016.12.039.

LAHAYE, Christelle; HERNANDEZ, Marion; BOËDA, Eric; FELICE, Gisele D.; GUIDON, Niède; HOELTZ, Sirlei; LORDEAU, Antoine; PAGLI, Marina; PESSIS, Anne-Marie; RASSE, Michel; VIANA, Sibeli. Human occupation in South America by 20,000 BC: the Toca da Tira Peia site, Piauí, Brazil. Journal of Archaeological Science, Amsterdam, v. 40, n. 6, p. 2840-2847, June 2013. DOI: https://doi.org/10.1016/j. jas.2013.02.019.

LAHR, Marta Mirazon. Patterns of modern human diversification: implications for Amerindian origins. Yearbook of Physical Anthropology, Hoboken, v. 38, p. 163-198, Jan. 1995. Supl. 21. DOI: https://doi.org/10.1002/ajpa.1330380609.

LARSEN, Clark Spencer. Bioarchaeology: interpreting behavior from the human skeleton. 2nd ed. Cambridge: Cambridge University Press, 2015.

LESSA, Andrea; GUIDON, Niède. Osteobiographic analysis of skeleton I, Sitio Toca dos Coqueiros, Serra da Capivara National Park, Brazil, 11,060 BP: first results. American Journal of Physical Anthropology, Hoboken, v. 118, n. 2, p. 99-110, June 2002. DOI: https://doi.org/10.1002/ajpa.10084.

LINDO, John; ACHILLI, Alessandro; PEREGO, Ugo A.; ARCHER, David; VALDIOSERA, Cristina; PETZELT, Barbara; MITCHELL, Joycelynn; WORL, Rosita; DIXON, E. James; FIFIELD, Terence E.; RASMUSSEN, Morten; WILLERSLEV, Eske; CYBULSKI, Jerome S.; KEMP, Brian M.; DEGIORGIO, Michael; MALHI, Ripan S. Ancient individuals from the North American Northwest Coast reveal 10,000 years of regional genetic continuity. PNAS, Washington, v. 114, n. 16, p. 4093-4098, Apr. 2017. DOI: https://doi.org/10.1073/pnas.1620410114.

LLAMAS, Bastien; FEHREN-SCHMITZ, Lars; VALVERDE, Guido; SOUBRIER, Julien; MALLICK, Swapan; ROHLAND, Nadin; NORDENFELT, Susanne; VALDIOSERA, Cristina; RICHARDS, Stephen M.; ROHRLACH, Adam; ROMERO, Maria Inés Barreto; FLORES ESPINOZA, Isabel; CAGIGAO, Elsa Tomasto; JIMÉNEZ, Lucía Watson; MAKOWSKI, Krzysztof; LEBOREIRO REYNA, Ilán Santiago; LORY, Josefina Mansilla; BALLIVIÁN TORREZ, Julio Alejandro; RIVERA, Mario A.; BURGER, Richard L.; CERUTI, Maria Constanza; REINHARD, Johan; WELLS, R. Spencer; POLITIS, Gustavo; SANTORO, Calogero M.; STANDEN, Vivien G.; SMITH, Colin; REICH, David; HO, Simon Y. H.; COOPER, Alan; HAAK, Wolfgang. Ancient mitochondrial DNA provides high-resolution time scale of the peopling of the Americas. Science Advances, Washington, v. 2, n. 4, p. e1501385, Apr. 2016. DOI: https://doi.org/10.1126/ sciadv. 1501385.

MACNEISH, Richard S.; VIERRA, Robert K.; NELKEN-TERNER, Antoinette; LURIE, Rochelle; COOK, Angel Garcia (org.). Prehistory of the Ayacucho Basin, Peru: the preceramic way of life. Michigan: The University of Michigan Press, 1983. v. IV.

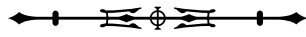


MALASPINAS, Anna-Sapfo; LAO, Oscar; SCHROEDER, Hannes; RASMUSSEN, Morten; RAGHAVAN, Maanasa; MOLTKE, Ida; CAMPOS, Paula, F; SAGREDO, Francisca Santana; RASMUSSEN, Simon; GONÇALVES, Vanessa F; ALBRECHTSEN, Anders; ALLENTOFT, Morten E.; JOHNSON, Philip L. F.; LI, Mingkun; REIS, Silvia; BERNARDO, Danilo V.; DEGIORGIO, Michael; DUGGAN, Ana T.; BASTOS, Murilo; WANG, Yong; STENDERUP, Jesper; MORENO-MAYAR, J. Victor; BRUNAK, Søren; SICHERITZPONTEN, Thomas; HODGES, Emily; HANNON, Gregory J.; ORLANDO, Ludovic; PRICE, T. Douglas; JENSEN, Jeffrey D.; NIELSEN, Rasmus; HEINEMEIER, Jan; OLSEN, Jesper; RODRIGUES-CARVALHO, Claudia; LAHR, Marta Mirazón; NEVES, Walter Alves; KAYSER, Manfred; HIGHAM, Thomas; STONEKING, Mark; PENA, Sergio D. J.; WILLERSLEV, Eske. Two ancient human genomes reveal Polynesian ancestry among the indigenous Botocudos of Brazil. Current Biology, Cambridge, v. 24, n. 21, p. R1035-R1037, Nov. 2014. DOI: https://doi.org/10.1016/j. cub.2014.09.078.

MANICA, Andrea; AMOS, William; BALLOUX, François; HANIHARA, Tsunehiko. The effect of ancient population bottlenecks on human phenotypic variation. Nature, London, v. 448, n. 7151, p. 346-349, July 2007. DOI: https://doi.org/10.1038/nature05951.

MARINHO, Anderson Nonato do Rosário; MIRANDA, Newton Cardoso; BRAZ, Valéria; RIBEIRO-DOS-SANTOS, Andrea Kely; MENDONÇA DE SOUZA, Sheila Maria Ferraz. Paleogenetic and taphonomic analysis of human bones from Moa, Beirada, and Zé Espinho Sambaquis, Rio de Janeiro, Brazil. Memórias do Instituto Oswaldo Cruz, Rio de Janeiro, v. 101, p. 15-24, dez. 2006. Supl. 2. DOI: https://doi.org/10.1590/s0074-02762006001000004.

MARLOWE, Frank W. Hunting and gathering: the human sexual division of foraging labor. Cross Cultural Research, Thousand Oaks, v. 41, n. 2, p. 170-195, May 2007. DOI: https://doi. org/10.1177/1069397106297529.

MARTIN, Paul S. The discovery of America. Science, Washington, v. 179, n. 4077, p. 969-974, Mar. 1973. DOI: https://doi.org/10.1126/ science.179.4077.969.

MELTZER, David J.; ADOVASIO, James M.; DILLEHAY, Tom D. On a Pleistocene human occupation at Pedra Furada, Brazil. Antiquity, Cambridge, v. 68, n. 261, p. 695-714, Dec. 1994. DOI: https://doi. org/10.1017/S0003598X00047414.

MENDONÇA DE SOUZA, Sheila Maria Ferraz. O silêncio bioarqueológico da Amazônia: entre o mito da diluição demográfica e o da diluição biológica na floresta tropical. In: PEREIRA, Edith; GUAPAINDAIA, Vera (org.). Arqueologia Amazônica. Belém: MPEG, 2010. v. 1, p. 427-445.

MENÉNDEZ, Lumila; BERNAL, Valeria; NOVELLINO, Paula; PEREZ, S. Ivan. Effect of bite force and diet composition on craniofacial diversification variation on Southern South American populations. American Journal of Physical Anthropology, Hoboken, v. 155, n. 1, p. 114-127, Sept. 2014. DOI: https://doi. org/10.1002/ajpa.22560.
MERRIWETHER, David Andrew; ROTHHAMMER, Francisco; FERRELL, Robert. Distribution of the four-founding lineage haplotypes in Native Americans suggests a single wave of migration for the New World. American Journal of Physical Anthropology, Hoboken, v. 98, n. 4, p. 411-430, Dec. 1995. DOI: https://doi. org/10.1002/ajpa.1330980404.

MILLER, D. Shane; HOLLIDAY, Vance T.; BRIGHT, Jordon. Clovis across the continent. In: GRAF, Kelly E.; KETRON, Caroline V.; WATERS, Michael R. (ed.). Paleoamerican odyssey. College Station: Texas A\&M University Press, 2013. p. 207-220.

MONTENEGRO, Alvaro; ARAUJO, Adauto; EBY, Michael; FERREIRA, Luiz Fernando; HETHERINGTON, Renée; WEAVER, Andrew J. Parasites, paleoclimate and the peopling of the Americas: using the hookworm to time the Clovis migration. Current Anthropology, Chicago, v. 47, n. 1, p. 193-198, Feb. 2006. DOI: https://doi.org/10.1086/499553.

MORENO-MAYAR, J. Víctor; POTTER, Ben A.; VINNER, Lasse; STEINRÜCKEN, Matthias; RASMUSSEN, Simon; TERHORST, Jonathan; KAMM, John A.; ALBRECHTSEN, Anders; MALASPINAS, Anna-Sapfo; SIKORA, Martin; REUTHER, Joshua D.; IRISH, Joel D.; MALHI, Ripan S.; ORLANDO, Ludovic; SONG, Yun S.; NIELSEN, Rasmus; MELTZER, David J.; WILLERSLEV, Eske. Terminal Pleistocene Alaskan genome reveals first founding population of Native Americans. Nature, London, v. 553, n. 7687, p. 203-207, Jan. 2018a. DOI: https://doi.org/10.1038/nature25173.

MORENO-MAYAR, J. Víctor; VINNER, Lasse; DAMGAARD, Peter de Barros; FUENTE, Constanza de la; CHAN, Jeffrey; SPENCE, Jeffrey P.; ALLENTOFT, Morten E.; VIMALA, Tharsika; RACIMO, Fernando; PINOTTI, Thomaz; RASMUSSEN, Simon; MARGARYAN, Ashot; ORBEGOZO, Miren Iraeta; MYLOPOTAMITAKI, Dorothea; WOLLER, Matthew; BATAILLE, Clement; BECERRA-VALDIVIA, Lorena; CHIVALL, David; COMESKEY, Daniel; DEVIĖSE, Thibault; GRAYSON, Donald K.; GEORGE, Len; HARRY, Harold; ALEXANDERSEN, Verner; PRIMEAU, Charlotte; ERLANDSON, Jon; RODRIGUES-CARVALHO, Claudia; REIS, Silvia; BASTOS, Murilo Q. R.; CYBULSKI, Jerome; VULLO, Carlos; MORELLO, Flavia; VILAR, Miguel; WELLS, Spencer; GREGERSEN, Kristian; HANSEN, Kasper Lykke; LYNNERUP, Niels; LAHR, Marta Mirazón; KJAER, Kurt; STRAUSS, André; ALFONSO-DURRUTY, Marta; SALAS, Antonio; SCHROEDER, Hannes; HIGHAM, Thomas; MALHI, Ripan S.; RASIC, leffrey T.; SOUZA, Luiz; SANTOS, Fabricio R.; MALASPINAS, Anna-Sapfo; SIKORA, Martin; NIELSEN, Rasmus; SONG, Yun S.; MELTZER, David J.; WILLERSLEV, Eske. Early human dispersals within the Americas. Science, Washington, v. 362, n. 6419, p. eaav2621, Dec. 2018b. DOI: https://doi.org/10.1126/science.aav2621.

MORENO-MAYAR, J. Víctor; RASMUSSEN, Simon; SEGUINORLANDO, Andaine; RASMUSSEN, Morten; LIANG, Mason; FLAM, Siri Tennebø; LIE, Benedicte Alexandra; GILFILLAN, Gregor Duncan; NIELSEN, Rasmus; THORSBY, Eric; WILLERSLEV, Eske; MALASPINAS, Anna-Sapfo. Genome-wide ancestry patterns in Rapanui suggest pre-European admixture with Native Americans. Current Biology, Cambridge, v. 24, n. 21, p. 2518-2525, Nov. 2014. DOI: https://doi.org/10.1016/j.cub.2014.09.057.

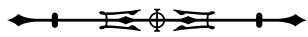


MORSE, Dan F. Sloan: a Paleoindian Dalton Cemetery in Arkansas. Washington: Smithsonian Institution, 1997.

NEVES, Walter Alves; HUBBE, Mark; STRAUSS, André Menezes; BERNARDO, Danilo Vicensotto. Morfologia craniana dos remanescentes ósseos humanos da Lapa do Santo, Lagoa Santa, Minas Gerais, Brasil: implicações para o povoamento das Américas. Boletim do Museu Paraense Emílio Goeldi. Ciências Humanas, Belém, v. 9, n. 3, p. 715-740, set./dez. 2014. DOI: http://dx.doi. org/10.1590/1981-81222014000300012.

NEVES, Walter Alves; HUBBE, Mark; BERNARDO, Danilo Vicensotto; STRAUSS, André; ARAUJO, Astolfo G. M.; KIPNIS, Renato. Early human occupation of Lagoa Santa, Eastern Central Brazil: craniometric variation of the initial settlers of South America. In: GRAF, Kelly E.; KETRON, Caroline V.; WATERS, Michael R. (ed.). Paleoamerican odyssey. College Station: Texas A\&M University Press, 2013. p. 397-414.

NEVES, Walter Alves; HUBBE, Mark; CORREAL, Gonzalo. Human skeletal remains from Sabana de Bogotá, Colombia: a case of Paleoamerican morphology late survival in South America? American Journal of Physical Anthropology, Hoboken, v. 133, n. 4, p. 10801098, Aug. 2007. DOI: https://doi.org/10.1002/ajpa.20637.

NEVES, Walter Alves; HUBBE, Mark. Cranial morphology of early Americans from Lagoa Santa, Brazil: implications for the settlement of the New World. PNAS, Washington, v. 102, n. 51, p. 1830918314, Dec. 2005. DOI: https://doi.org/10.1073/pnas.0507185102.

NEVES, Walter Alves; HUBBE, Mark; OKUMURA, Maria Mercedes M.; GONZÁLEZ-JOSÉ, Rolando; FIGUTI, Levy; EGGERS, Sabine; DE BLASIS, Paulo Antonio Dantas. A new early Holocene human skeleton from Brazil: implications for the settlement of the New World. Journal of Human Evolution, Amsterdam, v. 48, n. 4, p. 403414, Apr. 2005. DOI: https://doi.org/10.1016/j.jhevol.2004.12.001.

NEVES, Walter Alves; HUBBE, Mark; RIBEIRO, Pedro Augusto Mentz; BERNARDO, Danilo Vicensotto. Afinidades morfológicas de três crânios associados à tradição Umbu: uma análise exploratória multivariada. Revista do CEPA, Santa Cruz do Sul, v. 28, n. 39, p. 159-185, jan./jun. 2004.

NEVES, Walter Alves; PROUS, André; GONZÁLEZ-JOSÉ, Rolando; KIPNIS, Renato; POWELL, Joseph. Early human skeletal remains from Santana do Riacho, Brazil: implications for the settlement of the New World. Journal of Human Evolution, Amsterdam, v. 45, n. 1, p. 1942, July 2003. DOI: https://doi.org/10.1016/S0047-2484(03)00081-2.

NEVES, Walter Alves; POWELL, Joseph F; OZOLINS, Erik G. Extra-continental morphological affinities of Palli Aike, Southern Chile. Interciéncia, Caracas, v. 24, n. 4, p. 258-263, jul./ago. 1999a.

NEVES, Walter Alves; POWELL, Joseph F.; PROUS, Andre; OZOLINS, Erik G.; BLUM, Max. Lapa Vermelha IV Hominid 1: morphological affinities of the earliest known American. Genetics and Molecular Biology, São Paulo, v. 22, n. 4, p. 461-469, dez. 1999b. DOI: http://dx.doi.org/10.1590/S1415-47571999000400001.
NUNES, T. L. Afinidades biológicas extra-continentais dos Paleoíndios tardios de Lagoa Santa e suas implicações para a questão do povoamento do Novo Mundo: uma abordagem osteométrica. 2010. Dissertação (Mestrado em Genética e Biologia Evolutiva) - Universidade de São Paulo, São Paulo, 2010.

OLIVEIRA, Rodrigo Elias; DA-GLORIA, Pedro; NEVES, Walter Alves. A percepção do meio ambiente por parte da população atual de Lagoa Santa e suas implicações para a arqueologia regional. Revista de Arqueologia da SAB, Pelotas, v. 31, n. 1, p. 104-130, jun. 2018. DOI: https://doi.org/10.24885/sab.v31i1.537.

OPPENHEIMER, Stephen; BRADLEY, Bruce; STANFORD, Dennis. Solutrean hypothesis: genetics, the mammoth in the room. World Archaeology, London, v. 46, n. 5, p. 752-774, Oct. 2014. DOI: https://doi.org/10.1080/00438243.2014.966273.

OWSLEY, Douglas W.; WILLIAMS, Aleithea A.; BRUWELHEIDE, Karin S. Skeletal inventory, morphology, and pathology. In: OWSLEY, Douglas W.; JANTZ, Richard L. (ed.). Kennewick man: the scientific investigation of an ancient merican skeleton. College Station: Texas A\&M University Press, 2014. p. 139-186.

OWSLEY, Douglas W.; JODRY, Margaret A.; STAFFORD JÚNIOR, Thomas W.; HAYNES JÚNIOR, C. Vance; STANFORD, Dennis J. Arch Lake Woman: physical anthropology and geoarchaeology. College Station: Texas A\&M University Press, 2010.

PÄÄBO, Svant. Neanderthal man: in search of lost genomes. New York: Basic Books, 2014.

PARKER PEARSON, Mike. The Archaeology of death and burial. College Station: Texas A\&M University Press, 1999.

PEDERSEN, Mikkel W.; RUTER, Anthony; SCHWEGER, Charles; FRIEBE, Harvey; STAFF, Richard A.; KJELDSEN, Kristian K.; MENDOZA, Marie L. Z.; BEAUDOIN, Alwynne B.; ZUTTER, Cynthia; LARSEN, Nicolaj K.; POTTER, Ben A.; NIELSEN, Rasmus; RAINVILLE, Rebecca A.; ORLANDO, Ludovic; MELTZER, David J.; KJAER, Kurt H.; WILLERSLEV, Eske. Postglacial viability and colonization in North America's ice-free corridor. Nature, London, v. 537, n. 7618, p. 45-49, Sept. 2016. DOI: https://doi.org/10.1038/nature19085.

PEREGO, Ugo A.; ACHILLI, Alessandro; ANGERHOFER, Norman; ACCETTURO, Matteo; PALA, Maria; OLIVIERI, Ann; KASHANI, Baharak Hooshiar; RITCHIE, Kathleen H.; SCOZZARI, Rosaria; KONG, Qing-Peng; MYRES, Natalie M.; SALAS, Antonio; SEMINO, Ornella; BANDELT, Hans-Jürgen; WOODWARD, Scott R.; TORRONI, Antonio. Distinctive Paleo-Indian migration routes from Beringia marked by two rare mtDNA haplogroups. Current Biology, Cambridge, v. 19, n. 1, p. 1-8, Jan. 2009. DOI: https://doi.org/10.1016/J.cub.2008.11.058.

PEREZ, S. Ivan; LEMA, Verónica; DINIZ-FILHO, José Alexandre Felizola; BERNAL, Valeria; GONZALEZ, Paula N.; GOBBO, Diego; PUCCIARELLI, Héctor $M$. The role of diet and temperature in shaping cranial diversification of South American human populations: an approach based on spatial regression and divergence rate tests. Journal of Biogeography, Hoboken, v. 38, n. 1, p. 148-163, Jan. 2011. DOI: https://doi.org/10.1111/j.1365-2699.2010.02392.x.

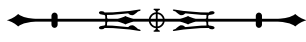


PEREZ, S. Ivan; MONTEIRO, Leandro R. Nonrandom factors in modern human morphological diversification: a study of craniofacial variation in southern South American populations. Evolution, Hoboken, v. 63, n. 4, p. 978-993, Apr. 2009. DOI: https://doi. org/10.1111/j.1558-5646.2008.00539.x.

PEYRE, Eveline. Nouvelle découverte d'un homme préhistorique américain: une femme de 9700 ans au Brésil. Comptes Rendus de l'Académie des Sciences, Paris, v. 316, p. 839-842, 1993.

POSTH, Cosimo; NAKATSUKA, Nathan; LAZARIDIS, Iosif; SKOGLUND, Pontus; MALLICK, Swapan; LAMNIDIS, Thiseas C.; ROHLAND, Nadin; NÄGELE, Kathrin; ADAMSKI, Nicole; BERTOLINI, Emilie; BROOMANDKHOSHBACHT, Nasreen; COOPER, Alan; CULLETON, Brendan J.; FERRAZ, Tiago; FERRY, Matthew; FURTWÄNGLER, Anja; HAAK, Wolfgang; HARKINS, Kelly; HARPER, Thomas K.; HÜNEMEIER, Tábita; LAWSON, Ann Marie; LLAMAS, Bastien; MICHEL, Megan; NELSON, Elizabeth; OPPENHEIMER, Jonas; PATTERSON, Nick; SCHIFFELS, Stephan; SEDIG, Jakob; STEWARDSON, Kristin; TALAMO, Sahra; WANG, Chuan-Chao; HUBLIN, Jean-Jacques; HUBBE, Mark; HARVATI, Katerina; DELAUNAY, Amalia Nuevo; BEIER, Judith; FRANCKEN, Michael; KAULICKE, Peter; REYES-CENTENO, Hugo; RADEMAKER, Kurt; TRASK, Willa R.; ROBINSON, Mark; GUTIERREZ, Said M.; PRUFER, Keith M.; SALAZAR-GARCÍA, Domingo C.; CHIM, Eliane N.; GOMES, Lisiane Müller Plumm; ALVES, Marcony L.; LIRYO, Andersen; INGLEZ, Mariana; OLIVEIRA, Rodrigo E.; BERNARDO Danilo Vicensotto; BARIONI, Alberto; WESOLOWSKI, Veronica; SCHEIFLER, Nahuel A.; RIVERA, Mario A.; PLENS, Claudia R.; MESSINEO, Pablo G.; FIGUTI, Levy; CORACH, Daniel; SCABUZZO, Clara; EGGERS, Sabine; DEBLASIS, Paulo; REINDEL, Markus; MÉNDEZ, César; POLITIS, Gustavo; TOMASTO-CAGIGAO, Elsa; KENNETT, Douglas J.; STRAUSS, André; FEHREN-SCHMITZ, Lars; KRAUSE, Johannes; REICH, David. Reconstructing the deep population history of Central and South America. Cell, Cambridge, v. 175, n. 5 , p. 1-13, Nov. 2018. DOI: https://doi.org/10.1016/J.cell.2018.10.027.

POTTER, Ben A.; IRISH, Joel D.; REUTHER, Joshua D.; MCKINNEY, Holly J. New insights into Eastern Beringian mortuary behavior: a terminal Pleistocene double infant burial at Upward Sun River. PNAS, Washington, v. 111, n. 48, p. 17060-17065, Dec. 2014. DOI: https:// doi.org/10.1073/pnas.1413131111.

POWELL, Joseph F. The first Americans: race, evolution, and the origin of Native Americans. Cambridge: Cambridge University Press, 2005.

POWELL, Joseph F; STEELE, D. Gentry. Diet and health of Paleoindians: an examination of Early Holocene human dental remains. In: SOBOLIK, Kristin D. (ed.). Paleonutrition: the diet and health of Prehistoric Americans. Carbondale: Center for Archaeological Investigations, 1994. p. 178-194. (Occasional Paper, 22).

PUCCIARELLI, Héctor M.; PEREZ, S. Ivan; POLITIS, Gustavo G. Early Holocene human remains from the Argentinean Pampas: additional evidence for distinctive cranial morphology of early South Americans. American Journal of Physical Anthropology, Hoboken, v. 143, n. 3, p. 298-305, Oct. 2010. DOI: https://doi.org/10.1002/ ajpa.21347
RAFF, Jennifer A.; BOLNICK, Deborah A. Does mitochondrial haplogroup $X$ indicate ancient Trans-Atlantic migration to the Americas? A critical re-evaluation. PaleoAmerica, London, v. 1, n. 4, p. 297-304, Oct. 2015. DOI: https://doi.org/10.1179/20555563 15Z.00000000040.

RAGHAVAN, Maanasa; STEINRÜCKEN, Matthias; HARRIS, Kelley; SCHIFFELS, Stephan; RASMUSSEN, Simon; DEGIORGIO, Michael; ALBRECHTSEN, Anders; VALDIOSERA, Cristina; ÁVILA-ARCOS, María C.; MALASPINAS, Anna-Sapfo; ERIKSSON, Anders; MOLTKE, Ida; METSPALU, Mait; HOMBURGER, Julian R.; WALL, Jeff; CORNEJO, Omar E.; MORENO-MAYAR, Víctor; KORNELIUSSEN, Thorfinn S.; PIERRE, Tracey; RASMUSSEN, Morten; CAMPOS, Paula F; DAMGAARD, Peter Barros de; ALLENTOFT, Morten E.; LINDO, John; METSPALU, Ene; RODRÍGUEZ-VARELA, Ricardo; MANSILLA, Josefina; HENRICKSON, Celeste; SEGUINORLANDO; Andaine; MALMSTRÖM, Helena; STAFFORD JÚNIOR, Thomas; SHRINGARPURE, Suyash S.; MORENOESTRADA, Andrés; KARMIN, Monika; TAMBETS, Kristiina; BERGSTRÖM, Anders; XUE, Yali; WARMUTH, Vera; FRIEND, Andrew; SINGARAYER, Joy; VALDES, Paul; BALLOUX, Francois; LEBOREIRO, Ilán; VERA, Jose Luis; RANGEL-VILLALOBOS, Hector; PETTENER, Davide; LUISELLI, Donata; DAVIS, Loren G.; HEYER, Evelyne; ZOLLIKOFER, Christoph P. E.; PONCE DE LEÓN, Marcia S.; SMITH, Colin I.; GRIMES, Vaughan; PIKE, KellyAnne; DEAL, Michael; FULLER, Benjamin; ARRIAZA, Bernardo; STANDEN, Vivien; LUZ, Maria F.; RICAUT, Francois; GUIDON, Niède; OSIPOVA, Ludmila P.; VOEVODA, Mikhail I.; POSUKH, Olga L.; BALANOVSKY, Oleg; LAVRYASHINA, Maria; BOGUNOV, Yuri; KHUSNUTDINOVA, Elza; GUBINA, Marina; BALANOVSKA, Elena; FEDOROVA, Sardana; LITVINOV, Sergey; MALYARCHUK, Boris; DERENKO, Miroslava; MOSHER, M. J.; ARCHER, David; CYBULSKI, Jerome; PETZELT, Barbara; MITCHELL, Joycelynn; WORL, Rosita; NORMAN, Paul J.; PARHAM, Peter; KEMP, Brian M.; KIVISILD, Toomas; TYLER-SMITH, Chris; SANDHU, Manjinder S.; CRAWFORD, Michael; VILLEMS, Richard; SMITH, David Glenn; WATERS, Michael R.; GOEBEL, Ted; JOHNSON, John R.; MALHI, Ripan, S.; JAKOBSSON, Mattias; MELTZER, David J.; MANICA, Andrea; DURBIN, Richard; BUSTAMANTE, Carlos D.; SONG, Yun S.; NIELSEN, Rasmus; WILLERSLEV, Eske. Genomic evidence for the Pleistocene and recent population history of Native Americans. Science, Washington, v. 349, n. 6250, p. aab3884, Aug. 2015. DOI: https://doi.org/10.1126/science.aab3884.

RAGHAVAN, Maanasa; SKOGLUND, GRAF, Pontus; Kelly E.; METSPALU, Mait; ALBRECHTSEN, Anders; MOLTKE, Ida; RASMUSSEN, Simon; STAFFORD JÚNIOR, Thomas W.; ORLANDO, Ludovic; METSPALU, Ene; KARMIN, Monika; TAMBETS, Kristiina; ROOTSI, Siiri; MÄGI, Reedik; CAMPOS, Paula F; BALANOVSKA, Elena; BALANOVSKY, Oleg; KHUSNUTDINOVA, Elza; LITVINOV, Sergey; OSIPOVA, Ludmila P.; FEDOROVA, Sardana A.; VOEVODA, Mikhail I.; DEGIORGIO, Michael; SICHERITZPONTEN, Thomas; BRUNAK, Søren; DEMESHCHENKO, Svetlana; KIVISILD, Toomas; VILLEMS, Richard; NIELSEN, Rasmus; JAKOBSSON, Mattias; WILLERSLEV, Eske. Upper Palaeolithic Siberian genome reveals dual ancestry of Native Americans. Nature, London, v. 505, n. 7481, p. 87-91, Jan. 2014. DOI: https://doi. org/10.1038/nature12736.

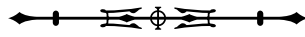


RASMUSSEN, Morten; SIKORA, Martin; ALBRECHTSEN, Anders; KORNELIUSSEN, Thorfinn Sand; MORENO-MAYAR, J. Víctor; POZNIK, G. David; ZOLLIKOFER, Christoph P. E.; PONCE DE LEÓN, Marcia S.; ALLENTOFT, Morten E.; MOLTKE, Ida; JÓNSSON, Hákon; VALDIOSERA, Cristina; MALHI, Ripan S.; ORLANDO, Ludovic; BUSTAMANTE, Carlos D.; STAFFORD JÚNIOR, Thomas W.; MELTZER, David J.; NIELSEN, Rasmus; WILLERSLEV, Eske. The ancestry and affiliations of Kennewick Man. Nature, London, v. 523, p. 455-458, July 2015.

RASMUSSEN, Morten; ANZICK, Sarah L.; WATERS, Michael R.; SKOGLUND, Pontus; DEGIORGIO, Michael; STAFFORD JÚNIOR, Thomas W.; RASMUSSEN, Simon; MOLTKE, Ida; ALBRECHTSEN, Anders; DOYLE, Shane M.; POZNIK, G. David; GUDMUNDSDOTTIR, Valborg; YADAV, Rachita; MALASPINAS; Anna-Sapfo; WHITE, Samuel Stockton; ALLENTOFT, Morten E.; CORNEJO, Omar E.; TAMBETS, Kristiina; ERIKSSON, Anders; HEINTZMAN, Peter D.; KARMIN, Monika; KORNELIUSSEN, Thorfinn Sand; MELTZER, David J.; PIERRE, Tracey L.; STENDERUP, Jesper; SAAG, Lauri; WARMUTH, Vera M.; LOPES, Margarida C.; MALHI, Ripan S.; BRUNAK, Søren; SICHERITZPONTEN, Thomas; BARNES, Ian; COLLINS, Matthew; ORLANDO, Ludovic; BALLOUX, Francois; MANICA, Andrea; GUPTA, Ramneek; METSPALU, Mait; BUSTAMANTE, Carlos D.; JAKOBSSON, Mattias; NIELSEN, Rasmus; WILLERSLEV, Eske. The genome of a Late Pleistocene human from a Clovis burial site in western Montana. Nature, London, v. 506, p. 225-229, Feb. 2014.

REICH, David; PATTERSON, Nick; CAMPBELL, Desmond; TANDON, Arti; MAZIERES, Stéphane; RAY, Nicolas; PARRA, Maria V.; ROJAS, Winston; DUQUE, Constanza; MESA, Natalia; GARCÍA, Luis F.; TRIANA, Omar; BLAIR, Silvia; MAESTRE, Amanda; DIB, Juan C.; BRAVI, Claudio M.; BAILLIET, Graciela; CORACH, Daniel; HÜNEMEIER, Tábita; BORTOLINI, Maria Cátira; SALZANO, Francisco M.; PETZL-ERLER, María Luiza; ACUÑA-ALONZO, Victor; AGUILAR-SALINAS, Carlos; CANIZALES-QUINTEROS, Samuel; TUSIÉ-LUNA, Teresa; RIBA, Laura; RODRÍGUEZ-CRUZ, Maricela; LOPEZ-ALARCÓN, Mardia; CORAL-VAZQUEZ, Ramón; CANTO-CETINA, Thelma; SILVA-ZOLEZZI, Irma; FERNANDEZ-LOPEZ, Juan Carlos; CONTRERAS, Alejandra V.; JIMENEZ-SANCHEZ, Gerardo; GÓMEZ-VÁZQUEZ, Maria José; MOLINA, Julio; CARRACEDO, Ángel; SALAS, Antonio; GALLO, Carla; POLETTI, Giovanni; WITONSKY, David B.; ALKORTA-ARANBURU, Gorka; SUKERNIK, Rem I.; OSIPOVA, Ludmila; FEDOROVA, Sardana A.; VASQUEZ, René; VILLENA, Mercedes; MOREAU, Claudia; BARRANTES, Ramiro; PAULS, David; EXCOFFIER, Laurent; BEDOYA, Gabriel; ROTHHAMMER, Francisco; DUGOUJON, Jean-Michel; LARROUY, Georges; KLITZ, William; LABUDA, Damian; KIDD, Judith; KIDD, Kenneth; DI RIENZO, Anna; FREIMER, Nelson B.; PRICE, Alkes L.; RUIZLINARES, Andrés. Reconstructing Native American population history. Nature, London, v. 488, p. 370-374, Aug. 2012.

RELETHFORD, John H. Population-specific deviations of global human craniometric variation from a neutral model. American Journal of Physical Anthropology, Hoboken, v. 142, n. 1, p. 105111, May 2010. DOI: https://doi.org/10.1002/ajpa.21207.
RELETHFORD, John $\mathrm{H}$. Apportionment of global human genetic diversity based on craniometrics and skin color. American Journal of Physical Anthropology, Hoboken, v. 118, n. 4, p. 393-398, Aug. 2002. DOI: https://doi.org/10.1002/ajpa.10079.

RIBEIRO-DOS-SANTOS, A. K. C.; LEITE, D. S.; SANTOS, D. S. dos. DNA mitocondrial de populações humanas pré-colombianas da Amazônia. In: PEREIRA, Edith; GUAPINDAIA, Vera (org.). Arqueologia Amazônica. Belém: MPEG: IPHAN, 2010. v. 1, p. 449-468.

RIVET, P. Les origines de l'Homme Américain. Journal de la Société Des Américanistes, Paris, t. 46, p. 231, 1957.

ROSEMAN, Charles C. Detecting interregionally diversifying natural selection on modern human cranial form by using matched molecular and morphometric data. PNAS, Washington, v. 101, n. 35, p. 12824-12829, Aug. 2004. DOI: https://doi.org/10.1073/ pnas.0402637101.

SALZANO, F. M; CALLEGARI-JACQUES, S. M. South American Indians: a case study in evolution. Oxford: Clarendon Press, 1988.

SANTORO, Calogero M.; STANDEN, Vivien G.; ARRIAZA, Bernardo T.; DILLEHAY, Tom D. Archaic funerary pattern or postdepositional alteration? The Patapatane Burial in the highlands of South Central Andes. Latin American Antiquity, Washington, v. 16, n. 3, p. 329-346, Sept. 2005. DOI: https:// doi.org/10.2307/30042497.

SCALLY, Aylwyn; DURBIN, Richard. Revising the human mutation rate: implications for understanding human evolution. Nature Review Genetics, London, v. 13, n. 10, p. 745-753, Sept. 2012.

SCHEIB, C. L.; LI, H.; DESAI, Tariq; LINK, Vivian; KENDALL, Christopher; DEWAR, Genevieve; GRIFFITH, Peter William; MÖRSEBURG, Alexander; JOHNSON, John R.; POTTER, Amiee; KERR, Susan L.; ENDICOTT, Phillip; LINDO, John; HABER, Marc; XUE, Yali; TYLER-SMITH, Chris; SANDHU, Manjinder S.; LORENZ, Joseph G.; RANDALL, Tori D.; FALTYSKOVA, Zuzana; PAGANI, Luca; DANECEK, Petr; CONNELL, Tamsin C. O'; MARTZ, Patricia; BORAAS, Alan S.; BYRD, Brian F.; LEVENTHAL, Alan; CAMBRA, Rosemary; WILLIAMSON, Ronald; LESAGE, Louis; HOLGUIN, Brian; SOTO, Ernestine Ygnacio-De; ROSAS, John Tommy; METSPALU, Mait; STOCK, Jay T.; MANICA, Andrea; SCALLY, Aylwyn; WEGMANN, Daniel; MALHI, Ripan S.; KIVISILD, Toomas. Ancient human parallel lineages within North America contributed to a coastal expansion. Science, Washington, v. 360, n. 6392, p. 1024-1027, June 2018. DOI: $10.1126 /$ science.aar6851.

SCHURR, Theodore G. Tracking genes through time and space: changing perspective on new world origins. In: BONNICHSEN, Robson; LEPPER, Bradley T.; STANFORD, Dennis; WATERS, Michael R. (ed.). Paleoamerican origins: Beyond Clovis. College Station: Texas A\&M University Press, 2005. p. 221-242.

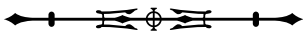


SCHURR, Theodore G.; BALLINGER, Scott W.; GAN, Yik-Yuen; HODGE, Judith A.; MERRIWETHER, D. Andrew; LAWRENCE, Dale N.; KNOWLER, William C.; WEISS, Kenneth M.; WALLACE, Douglas C. Amerindian mitochondrial DNAs have rare Asian mutations at high frequencies, suggesting they derived from four primary maternal lineages. American Journal of Human Genetics, Amsterdam, v. 46, n. 3, p. 613-623, Mar. 1990

SCHWARCZ, Henry P.; STAFFORD JÚNIOR, Thomas W.; KNYF, Martin; CHISHOLM, Brian; LONGSTAFFE, Fred J.; CHATTERS, James C.; OWSLEY, Douglas W. Stable isotopic evidence for diet and origin. In: OWSLEY, Douglas W.; JANTZ, Richard L. (ed.). Kennewick Man: the scientific investigation of an ancient american skeleton. College Station: Texas A\&M University Press, 2014. p. 310-322.

SCOTT, G. Richard; SCHMITZ, Kirk; HEIM, Kelly N.; PAUL, Katheen S.; SCHOMBERG, Roman; PILLOUD, Marin A. Sinodonty, Sundadonty, and the Beringian Standstill model: issues of timing and migrations into the new world. Quaternary International, Amsterdam, v. 466, p. 233-246, Feb. 2018. Part B. DOI: https:// doi.org/10.1016/j.quaint.2016.04.027.

SCOTT, G. Richard; TURNER II, Christy G. The anthropology of modern human teeth: dental morphology and its variation in recent human populations. Cambridge: Cambridge University Press, 1997.

SEGUCHI, Noriko; MCKEOWN, Ashley; SCHMIDT, Ryan; UMEDA, Hideyuki; BRACE, C. Loring. An alternative view of the peopling of South America: Lagoa Santa in craniometrics perspective. Anthropological Science, Japan, v. 119, n. 1, p. 21-38, Apr. 2011. DOI: https://doi.org/10.1537/ase.090921.

SILVA JÚNIOR, Wilson A.; BONATTO, Sandro L.; HOLANDA, Adriano l.; RIBEIRO-DOS-SANTOS, Andrea K.; PAIXÃO, Beatriz M.; GOLDMAN, Gustavo H.; ABE-SANDES, Kiyoko; RODRIGUEZDELFIN, Luis; BARBOSA, Marcela; PAÇÓ-LARSON, Maria Luiza; PETZL-ERLER, Maria Luiza; VALENTE, Valeria; SANTOS, Sidney E. B.; ZAGO, Marco A. Mitochondrial genome diversity of Native Americans supports a single early entry of founder populations into America. American Journal of Human Genetics, Amsterdam, v. 71, n. 1, p. 187-192, July 2002. DOI: https://doi.org/10.1086/341358.

SKOGLUND, Pontus; MALLICK, Swapan; BORTOLINI, Maria Cátira; CHENNAGIRI, Niru; HÜNEMEIER, Tábita; PETZL-ERLE, Maria Luiza; SALZANO, Francisco Mauro; PATTERSON, Nick; REICH, David. Genetic evidence for two founding populations of the Americas. Nature, London, v. 525, p. 104-108, Sept. 2015

SMALLWOOD, Ashley M.; JENNINGS, Thomas A.; PEVNY, Charlotte Donald. Expressions of ritual in the Paleoindian record of the Eastern Woodlands: exploring the uniqueness of the Dalton cemetery at Sloan, Arkansas. Journal of Anthropological Archaeology, Amsterdam, v. 49, p. 184-198, Mar. 2018. DOI: https:// doi.org/10.1016/j.jaa.2018.01.001.

STANFORD, Dennis ].; BRADLEY, Bruce A. Across Atlantic ice: the origin of America's Clovis culture. Berkeley: University of California Press, 2013.
STOJANOWSKI, Christopher M.; JOHNSON, Kent M. Observer error, dental wear, and the inference of New World Sundadonty. American Journal of Physical Anthropology, Hoboken, v. 156, n. 3, p. 349-362, Mar. 2015. DOI: https://doi.org/10.1002/ajpa.22653.

STRAUSS, André; OLIVEIRA, Rodrigo Elias; VILLAGRAN, Ximenes S.; BERNARDO, Danilo V.; SALAZAR-GARCÍA, Domingo C.; BISSARO JÚNIOR, Marcos César; PUGLIESE, Francisco; HERMENEGILDO, Tiago; SANTOS, Rafael; BARIONI, Alberto; OLIVEIRA, Emiliano Castro de; SOUSA, João Carlos Moreno; JAOUEN, Klervia; ERNANI, Max; HUBBE, Mark; INGLEZ, Mariana; GRATÃO, Marina; ROCKWELL, H.; MACHADO, Márcia; SOUZA, Gustavo de; CHEMALE, Farid; KAWASHITA, Koji; CONNELL, Tamsin C. O'.; ISRAD, Isabel; FEATHERS, James; CAMPI, Claudio; RICHARDS, Michael; WAHL, Joachim; KIPNIS, Renato; ARAUJO, Astolfo; NEVES, Walter. Early Holocene ritual complexity in South America: the archaeological record of Lapa do Santo (east-central Brazil). Antiquity, Cambridge, v. 90, n. 354, p. 1454-1473, Dec. 2016. DOI: https://doi.org/10.15184/aqy.2016.220

STRAUSS, André; HUBBE, Mark; NEVES, Walter A.; BERNARDO, Danilo V.; ATUÍ, João Paulo V. The cranial morphology of the Botocudo Indians, Brazil. American Journal of Physical Anthropology, Hoboken, v. 157, n. 2, p. 202-216, June 2015 a.

STRAUSS, André; OLIVEIRA, Rodrigo Elias; BERNARDO, Danilo V.; SALAZAR-GARCÍA, Domingo C.; TALAMO, Sahra; JAOUEN, Klervia; HUBBE, Mark; BLACK, Sue; WILKINSON, Caroline; RICHARDS, Michael Phillip; ARAUJO, Astolfo G. M.; KIPNIS, Renato; NEVES, Walter Alves. The oldest case of decapitation in the New World (Lapa do Santo, East-Central Brazil). PLoS ONE, San Francisco, v. 10, n. 9, p. 1-31, Sept. 2015b. DOI: https://doi. org/10.1371/journal.pone.0137456.

STRAUSS, André. As práticas mortuárias dos primeiros sulamericanos. Arquivos do Museu de História Natural e Jardim Botânico, Belo Horizonte, v. 23, n. 1, p. 89-134, 2014.

SUTTER, Richard C. The prehistoric peopling of the South America as inferred from epigenetic traits. Andean Past, Maine, v. 7, p. 183217, Jan. 2005

TAMM, Erika; KIVISILD, Toomas; REIDLA, Maere; METSPALU, Mait; SMITH, David Glenn; MULLIGAN, Connie; BRAVI, Claudio M.; RICKARDS, Olga; MARTINEZ-LABARGA, Cristina; KHUSNUTDINOVA, Elsa K.; FEDOROVA, Sardana A.; GOLUBENKO, Maria V.; STEPANOV, Vadim A.; GUBINA, Marina A.; ZHADANOV, Sergey I.; OSSIPOVA, Ludmila P.; DAMBA, Larisa; VOEVODA, Mikhail I.; DIPIERRI, Jose E.; VILLEMS, Richard; MALHI, Ripan S. Beringian standstill and spread of Native American founders. PloS ONE, San Francisco, v. 2, n. 9, p. 1-6, Sept. 2007. DOI: https:// doi.org/10.1371/journal.pone.0000829.

TORRONI, Antonio; NEEL, James V.; BARRANTES, Ramiro; SCHURR, Theodore G.; WALLACE, Douglas C. Mitochondrial DNA "clock" for the Amerinds and its implications for timing their entry into North America. PNAS, Washington, v. 91, n. 3, p. 11581162, Feb. 1994.

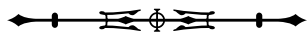


TORRONI, Antonio; SCHURR, Theodore G.; CABELL, Margaret F; BROWN, Michael D.; NEEL, James V.; LARSEN, Merethe; SMITH, David G.; VULLO, Carlos M.; WALLACE, Douglas C. Asian affinities and the continental radiation of the four founding Native American mtDNAs. American Journal of Human Genetics, Amsterdam, v. 53, p. 563-590, Sept. 1993.

TOWNSEND, Grant; HUGHES, Toby; LUCIANO, Michelle; BOCKMANN, Michelle; BROOK, Alan. Genetic and environmental influences on human dental variation: a critical evaluation of studies involving twins. Archives of Oral Biology, Amsterdam, v. 54, p. S45-S51, Aug. 2009. Supplement 1. DOI: https://doi.org/10.1016/j. archoralbio.2008.06.009.

TURBON, D.; ARENAS, C.; CUADRAS, C. M. Fueguian crania and the circum-Pacific rim variation. American Journal of Physical Anthropology, Hoboken, v. 163, n. 2, p. 295-316, June 2017. DOI: https://doi.org/10.1002/ajpa.23207.

TURNER II, Christy G. Major features of Sundadonty and Sinodonty, including suggestions about East Asia microevolution, population history, and Late Pleistocene relationships with Australian Aboriginals. American Journal of Physical Anthropology, Hoboken, v. 82, n. 3, p. 295-317, July 1990. DOI: https://doi.org/10.1002/ajpa.1330820308.

TURNER II, Christy G. Late Pleistocene and Holocene population history of east Asia based on dental variation. American Journal of Physical Anthropology, Hoboken, v. 73, n. 3, p. 305-321, July 1987. DOI: https://doi.org/10.1002/ajpa.1330730304.

VERGNE, Cleonice. Complexidade social e ritualidade funerária em Xingó: apontamentos teóricos para compreensão das práticas mortuárias do sítio Justino, Canindé de São Francisco - SE. Revista do Museu de Arqueologia de Xingó, Canindé, n. 9, p. 25-57, Jun. 2007.

VIALOU, Denis; BENABDELHADI, Mohammed; FEATHERS, James; FONTUGNE, Michel; VIALOU, Agueda Vilhena. Peopling South America's centre: the late Pleistocene site of Santa Elina. Antiquity, Cambridge, v. 91, n. 358, p. 865-884, Aug. 2017. DOI: https://doi. org/10.15184/aqy.2017.101.
WALTHALL, John A. Mortuary behavior and Early Holocene land use in the North American midcontinent. North American Archaeologist, Thousand Oaks, v. 20, n. 1, p. 1-30, Jan. 1999. DOI: https://doi.org/10.2190/MDEP-VM2K-YB2Q-L1D0.

WANG, Sijia; LEWIS JÚNIOR, Cecil M.; JAKOBSSON, Mattias; RAMACHANDRAN, Sohini; RAY, Nicolas; BEDOYA, Gabriel; ROJAS, Winston; PARRA, Maria V.; MOLINA, Julio A.; GALLO, Carla; MAZZOTTI, Guido; POLETTI, Giovanni; HILL, Kim; HURTADO, Ana M.; LABUDA, Damian; KLITZ, William; BARRANTES, Ramiro; BORTOLINI, Maria Cátira; SALZANO, Francisco M.; PETZL-ERLER, Maria Luiza; TSUNETO, Luiza T.; LLOP, Elena; ROTHHAMMER, Francisco; EXCOFFIER, Laurent; FELDMAN, Marcus W.; ROSENBERG, Noah A.; RUIZ-LINARES, Andrés. Genetic variation and population structure in native Americans. PLoS Genetics, San Francisco, v. 3, n. 11, p. 2049-2067, Nov. 2007. DOI: https://doi. org/10.1371/journal.pgen.0030185.

WOOLLER, Matthew J.; SAULNIER-TALBOT, Émilie; POTTER, Ben A.; BELMECHERI, Soumaya; BIGELOW, Nancy; CHOY, Kyungcheo; CWYNAR, Les C.; DAVIES, Kimberley; GRAHAM, Russell W.; KUREK, Joshua; LANGDON, Peter; MEDEIROS, Andrew; RAWCLIFFE, Ruth; WANG, Yue; WILLIAMS, John W. A new terrestrial palaeoenvironmental record from the Bering Land Bridge and context for human dispersal. Royal Society Open Science, London, v. 5, n. 6, p. 1-11, June 2018. DOI: https://doi. org/10.1098/rsos.180145.

ZEGURA, Stephen L.; KARAFET, Tatiana M.; ZHIVOTOVSKY, Lev A.; HAMMER, Michael F. High-resolution SNPs and microsatellite haplotypes point to a single, recent entry of Native American $Y$ chromosomes into the Americas. Molecular Biology and Evolution, Oxford, v. 21, n. 1, p. 164-175, Jan. 2004. DOI: https:// doi.org/10.1093/molbev/msh009.

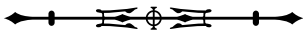


